\title{
Title: Unconditional cash transfers reduce homelessness
}

\author{
Authors: Ryan Dwyer ${ }^{1}$, Anita Palepu ${ }^{2}$, Claire Williams ${ }^{3}$, Jiaying Zhao ${ }^{1,4 *}$
}

\section{Affiliations:}

${ }^{1}$ Department of Psychology, University of British Columbia; Vancouver, Canada

${ }^{2}$ Department of Medicine, University of British Columbia; Vancouver, Canada

${ }^{3}$ Foundations for Social Change; Vancouver, Canada

${ }^{4}$ Institute for Resources, Environment and Sustainability, University of British Columbia; Vancouver, Canada

*Corresponding author. Email: jiayingz@psych.ubc.ca

\begin{abstract}
Homelessness is an economic and social crisis. In a cluster-randomized controlled trial, we address a core cause of homelessness - lack of money-by providing a one-time unconditional cash transfer of CAD\$7,500 to each of 50 individuals experiencing homelessness, with another 65 as controls in Vancouver, BC. Over one year, cash recipients spent fewer days homeless, increased savings and spending with no increase in temptation goods spending, and generated societal net savings of $\$ 777$ per recipient via reduced time in shelters. Additional experiments revealed public mistrust toward the ability of homeless individuals to manage money, and demonstrated interventions to increase public support for a cash transfer policy using counter-stereotypical or utilitarian messaging. Together, this research offers a potential approach to address homelessness and provides insights for homelessness reduction policies.
\end{abstract}

One-Sentence Summary: A one-time unconditional CAD\$7,500 cash transfer reduced homelessness and produced net savings via reduced social service use. 


\section{Main Text:}

The human toll of homelessness is profound. As 150 million people worldwide $-2 \%$ of the global population - currently experience homeless (1), they face increased risks of trauma, mental health challenges (2) and substance use disorders (3). The life expectancy of people experiencing homelessness is 8 to 13 years less than the general population (4). In addition to human costs, homelessness poses significant economic costs. The estimated societal cost of providing health and social services for individuals experiencing homelessness is between $\$ 55,000-\$ 132,000$ per person per year in Canada (5) and around $\$ 83,000$ in the US (6).

Traditional approaches to addressing homelessness have focused on the provision of emergency services (e.g., shelters), healthcare services (e.g., detox treatment), and permanent supportive housing (e.g., Housing First). While these essential programs help individuals avoid more severe forms of homelessness (7-9), they do not directly address a core cause: lack of money (10).

A growing body of research from low- and middle-income countries has demonstrated that cash transfers provide a range of benefits for low-income recipients, including improvement in physical health (11), psychological well-being (12), education and employment (13), and financial management (14). However, this approach has not been rigorously tested in highly vulnerable populations or in high-income countries due to policy and financial constraints. Building on past evidence, here we test the impact of unconditional cash transfers on individuals experiencing homelessness in Vancouver, British Columbia (BC), a city with a growing homeless population, rising housing costs, and low vacancy rates (15). This study provides a crucial proof of concept for providing cash transfers to recently homeless individuals in a highincome country. All experiments reported here received approval from the University of British Columbia Behavioural Research Ethics Board and were pre-registered on the Open Science Framework (see links in Data and Materials).

\section{Cash Transfer Experiment}

We conducted a cluster-randomized controlled trial (RCT) where individuals experiencing homelessness were assigned to receive a one-time cash transfer of CAD\$7,500 or not. This amount equaled the annual income assistance in British Columbia in 2016, and represented $59.6 \%$ of the average personal annual income $(\$ 12,580)$ of our participants. We established an agreement with the provincial government that ensured the cash transfer did not impact participants' existing or future benefits. The cash transfer was provided in a lump sum to enable maximum spending freedom and choice (e.g., rent, durable goods).

We recruited participants from 22 shelters across Metro Vancouver who met our eligibility criteria: age 19-65, homeless for less than two years, Canadian citizen or permanent resident, and non-severe levels of substance use (DAST-10) (16), alcohol use (AUDIT) (17), and mental health symptoms (CSI) (18). These criteria were used to reduce any potential risks of harm (e.g., overdose) from the cash transfer. To ensure accurate responses regarding the eligibility criteria, the initial recruitment was conducted without any mention of the cash transfer, and 115 eligible participants were successfully recruited into the study.

To mitigate potential risks (e.g., theft, assault) from providing different supports to participants within the same shelter, we performed random assignment at the shelter level, such that all participants recruited from a given shelter were assigned to the same condition. This stratified randomization procedure also balanced shelter partner organizations, shelter sizes and 
client demographics across conditions. In addition, all participants were offered honoraria for completing the surveys, a free checking account from a local credit union, replacement ID services, a resource booklet that outlined social services in the city, and a used smartphone.

After recruitment, all 115 participants completed a baseline survey that measured housing stability, finances, employment, education, food security, cognitive functioning, subjective wellbeing, and social service utilization. Participants in the cash group $(N=50)$ subsequently received the cash transfer into their checking account, and all participants were invited to complete follow-up surveys at 1, 3, 6, 9, and 12 months after the cash transfer. Survey dates for participants in the control group were yoked to cash participants to ensure similar timelines were followed across the two conditions. Details about methods, participant demographics, and balance checks are provided in Supplementary Materials.

Due to the novelty of this work, we pre-registered only a small set of confirmatory analyses predicting improved subjective well-being and cognitive function one month after the cash transfer for the cash group compared to control. None of the confirmatory analyses were significant (see Supplementary Materials). In more comprehensive exploratory analyses, we tested the impact of the cash transfer on all outcomes across the full 12-month study period. We removed outliers more than 3 standard deviations from the mean to reduce the influence of extreme and/or improbable data points, and we standardized outcomes into $z$-scores by subtracting each observation from the pooled mean across time points and then dividing it by the pooled standard deviation across time points. We then constructed 3-level linear mixed effects regression models to examine the interaction between conditions $(0=$ control, $1=$ cash $)$ and time, which was dummy coded to identify each time point treating baseline as the reference. Thus, the condition $\mathrm{x}$ time interaction estimates the standardized difference in mean changes from baseline to each follow-up time point. Our primary analyses test the overall effects of the cash transfer on the key outcomes of housing stability, assets, income, spending food security, employment, education, cognitive function, subjective well-being, substance use, and service use over 12 months, collapsing across follow-up time points and correcting for multiple comparisons using the Benjamini-Hochberg procedure (Figure 1) (19). Details about the analyses, along with sensitivity analyses that demonstrate the robustness of the results (e.g., including outliers, covariates, imputing data), are presented in Supplementary Materials.

Figure 1 shows the overall treatment effects over one year, measured as the difference between cash and control participants controlling for baseline. Over the year, cash recipients spent significantly fewer days homeless (e.g., shelter, streets; $b=-99)$ and marginally more days in stable housing (e.g., apartment; $b=55)$ than control participants. The difference in days was due to participants moving into other types of housing (e.g., transitional, institutional) between homelessness and stable housing. For cash recipients, the majority of time in stable housing was spent in apartment rentals $(74 \%)$ or single room occupancy units $(17 \%)$. For finances, cash recipients retained significantly more savings $(b=\$ 1,160)$ and increased monthly spending significantly more $(b=\$ 429)$ than control participants. Specifically, they spent more on durable goods (e.g., furniture, car), rent, food, and transit. Importantly, spending on temptation goods (i.e. alcohol, drugs, cigarettes) was not significantly different between groups. Although spending was measured through self-reports (adapted from 12), this result is consistent with prior cash transfer studies in lower-income countries (20). By reducing time in shelters, the cash transfer was cost-effective. The societal cost of a shelter stay in Vancouver is estimated at $\$ 93$ per night (5), so fewer nights $(b=-89)$ in shelters generated a societal cost savings of $\$ 8,277$. After accounting for the cost of the cash transfer, the reduced shelter use led to societal net 
savings of $\$ 777$ per participant a year. Alternatively, freed up shelter beds could be reallocated, so the benefits would trickle down by helping others avoid sleeping on the street.

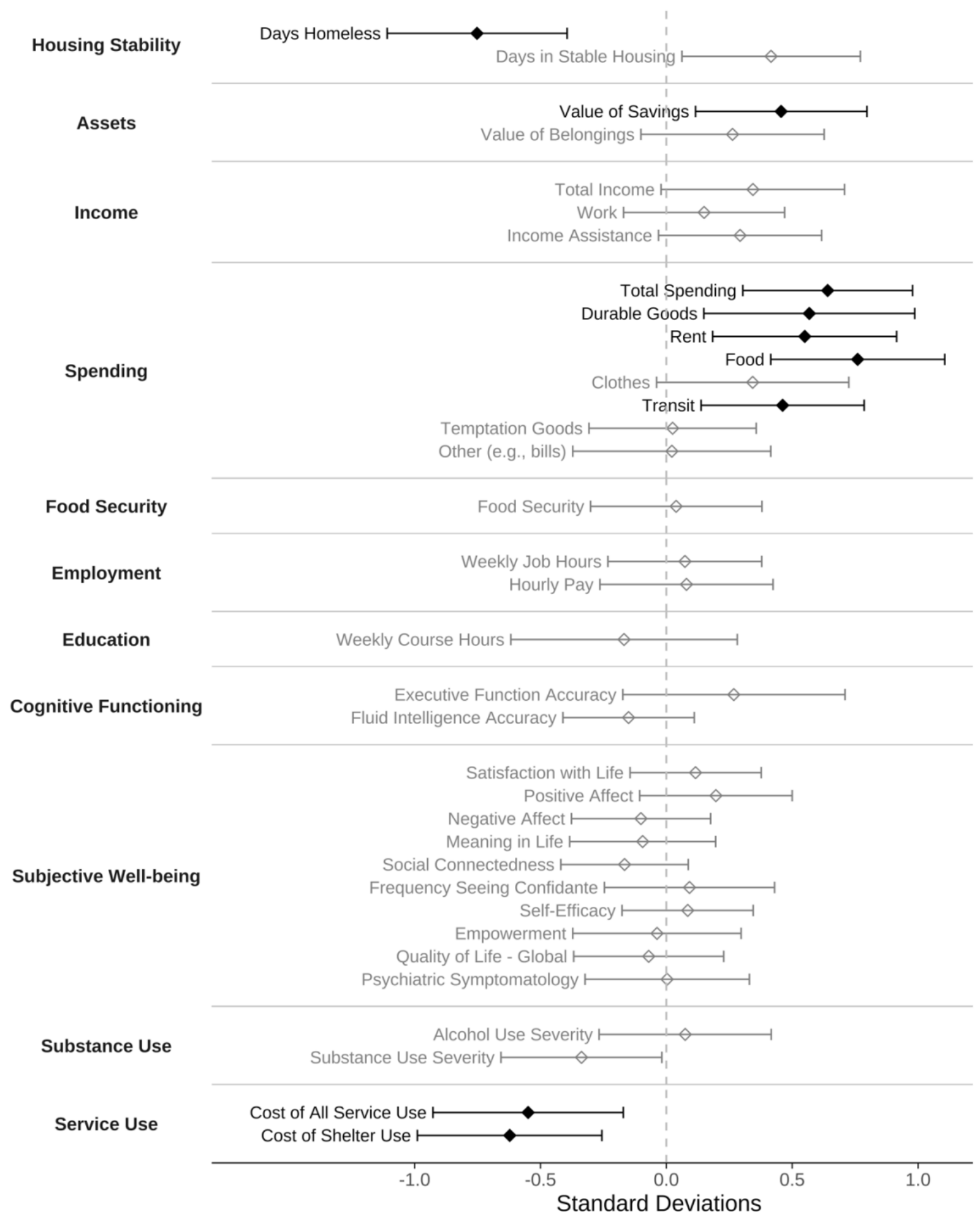

Figure 1. Overall treatment effects of cash compared to control groups pooled across follow-up time points over one year, while controlling for baseline levels (adjusted for multiple comparisons). Treatment effects are presented in standard deviations. $\downarrow$ = significant at $.05, \diamond=$ not significant at .05 . Error bars represent $95 \%$ confidence intervals. 
Our follow-up analyses examine the effect of the cash at each follow-up time point (Table 1). To promote discovery of potential effects from this rich data set, these follow-up analyses were not adjusted for multiple comparisons, and we emphasize the need for future work to confirm these findings. The analyses reveal that the significant overall effects were primarily driven by impacts within the first three months after the cash transfer. For example, the benefits in housing stability and spending were immediate, but diminished as the control group eventually gained stability over time (see Figure S3). The cash transfer did not have overall benefits or detriments on employment, cognitive function, subjective well-being, alcohol use severity, education, or food security, yet there were some significant short-term impacts on these outcomes. For example, more cash recipients achieved food security than control participants one month after the cash transfer. Cash recipients also showed higher positive affect at one month, had greater total income and showed higher accuracy on an executive function task at three months. The only detrimental effect reported was lower social connection at nine months, which could be due to moving to a new housing environment and a new community away from the shelter. There are several reasons the benefits of the cash transfer are most pronounced within the first three months. First, the cost of living is extremely high in Vancouver, and the majority of the cash was spent within the first three months for most recipients. Second, while the cash provided immediate benefits beyond the control group, control participants "caught up" over time. This is consistent with prior work showing that typical shelter clients exit the shelter system within 1-3 months using existing supports $(21,22)$. Finally, due to attrition and missed surveys, the sample size decreased over time, reducing statistical power to detect effects. Additional information related to these issues is provided in Table S3 and Figure S3 in the Supplemental Materials.

This experiment presents first evidence that a one-time unconditional cash transfer of $\$ 7,500$ has the potential to be an effective tool to reduce homelessness, increase housing stability, savings, and spending, and generate net savings for society via reduced social service use. Of course, there are limitations to this research (see Supplemental Materials), and these findings are based on exploratory analyses in a modestly sized sample that represents a high functioning subset (32\%) of the total homeless population in Vancouver. Thus, our results are preliminary and may not extend to those who are chronically homeless or experience higher severity of substance use, alcohol use, or psychiatric symptoms. Yet, this study provides proof of concept for the provision of cash assistance for marginalized groups, and offers promise for a new tool to address homelessness.

Table 1. Standardized treatment effects at each time point (unadjusted) and overall treatment effect (adjusted for multiple comparisons, pooled across time points) as regression coefficients and standard errors are shown in parenthesis. $(\dagger p<.1, * p<.05, * * p<.01, * * * p<.001)$

\begin{tabular}{|c|c|c|c|c|c|c|c|}
\hline Domain & Outcome & $1 \mathrm{~m}$ & $3 \mathrm{~m}$ & $6 \mathrm{~m}$ & $9 \mathrm{~m}$ & $12 \mathrm{~m}$ & Overall \\
\hline \multicolumn{8}{|c|}{ Housing Stability } \\
\hline & Days Homeless & $\begin{array}{l}-0.95 * * * \\
(0.21)\end{array}$ & $\begin{array}{l}-0.94 * * * \\
(0.21)\end{array}$ & $\begin{array}{l}-0.56^{*} \\
(0.22)\end{array}$ & $\begin{array}{l}-0.4 \dagger \\
(0.24)\end{array}$ & $\begin{array}{l}-0.3 \\
(0.24)\end{array}$ & $\begin{array}{l}-0.75^{* * *} \\
(0.18)\end{array}$ \\
\hline & Days in Stable Housing & $\begin{array}{l}0.64 * * \\
(0.21)\end{array}$ & $\begin{array}{l}0.61 * * \\
(0.22)\end{array}$ & $\begin{array}{l}0.32 \\
(0.22)\end{array}$ & $\begin{array}{l}-0.11 \\
(0.24)\end{array}$ & $\begin{array}{l}-0.01 \\
(0.24)\end{array}$ & $\begin{array}{l}0.42 \dagger \\
(0.18)\end{array}$ \\
\hline \multicolumn{8}{|l|}{ Assets } \\
\hline & Value of Savings & $\begin{array}{l}1.11 * * * \\
(0.21)\end{array}$ & $\begin{array}{l}0.58^{*} \\
(0.22)\end{array}$ & $\begin{array}{l}0.05 \\
(0.23)\end{array}$ & $\begin{array}{l}0.26 \\
(0.25)\end{array}$ & $\begin{array}{l}-0.17 \\
(0.26)\end{array}$ & $\begin{array}{l}0.46^{*} \\
(0.17)\end{array}$ \\
\hline & Value of Belongings & $\begin{array}{l}0.37 \\
(0.24)\end{array}$ & $\begin{array}{l}0.33 \\
(0.25)\end{array}$ & $\begin{array}{l}0.11 \\
(0.26)\end{array}$ & $\begin{array}{l}0.15 \\
(0.28)\end{array}$ & $\begin{array}{l}0.33 \\
(0.28)\end{array}$ & $\begin{array}{l}0.26 \\
(0.19)\end{array}$ \\
\hline
\end{tabular}




\begin{tabular}{|c|c|c|c|c|c|c|c|}
\hline Domain & Outcome & $1 \mathrm{~m}$ & $3 m$ & $6 \mathrm{~m}$ & $9 \mathrm{~m}$ & $12 \mathrm{~m}$ & Overall \\
\hline \multicolumn{8}{|l|}{ Income } \\
\hline & Total Income & $\begin{array}{l}0.01 \\
(0.23)\end{array}$ & $\begin{array}{l}0.56^{*} \\
(0.24)\end{array}$ & $\begin{array}{l}0.4 \\
(0.25)\end{array}$ & $\begin{array}{l}0.18 \\
(0.28)\end{array}$ & $\begin{array}{l}0.47 \dagger \\
(0.28)\end{array}$ & $\begin{array}{l}0.34 \\
(0.19)\end{array}$ \\
\hline & Work & $\begin{array}{l}0.07 \\
(0.21)\end{array}$ & $\begin{array}{l}0.23 \\
(0.22)\end{array}$ & $\begin{array}{l}0.23 \\
(0.23)\end{array}$ & $\begin{array}{l}0.05 \\
(0.25)\end{array}$ & $\begin{array}{l}0.02 \\
(0.25)\end{array}$ & $\begin{array}{l}0.15 \\
(0.16)\end{array}$ \\
\hline & Income Assistance & $\begin{array}{l}0.23 \\
(0.21)\end{array}$ & $\begin{array}{l}0.38 \dagger \\
(0.22)\end{array}$ & $\begin{array}{l}0.2 \\
(0.22)\end{array}$ & $\begin{array}{l}0.59^{*} \\
(0.24)\end{array}$ & $\begin{array}{l}0.16 \\
(0.24)\end{array}$ & $\begin{array}{l}0.29 \\
(0.16)\end{array}$ \\
\hline \multicolumn{8}{|l|}{ Spending } \\
\hline & Total Spending & $\begin{array}{l}0.99 * * * \\
(0.22)\end{array}$ & $\begin{array}{l}0.8^{* * * *} \\
(0.23)\end{array}$ & $\begin{array}{l}0.43 \dagger \\
(0.23)\end{array}$ & $\begin{array}{l}0.22 \\
(0.26)\end{array}$ & $\begin{array}{l}0.47 \dagger \\
(0.26)\end{array}$ & $\begin{array}{l}0.64 * * * \\
(0.17)\end{array}$ \\
\hline & Durable Goods & $\begin{array}{l}1.01 * * * \\
(0.28)\end{array}$ & $\begin{array}{l}0.89 * * \\
(0.29)\end{array}$ & $\begin{array}{l}0.42 \\
(0.29)\end{array}$ & $\begin{array}{l}-0.1 \\
(0.31)\end{array}$ & $\begin{array}{l}0.39 \\
(0.32)\end{array}$ & $\begin{array}{l}0.57 * \\
(0.21)\end{array}$ \\
\hline & Rent & $\begin{array}{l}0.78 * * \\
(0.22)\end{array}$ & $\begin{array}{l}0.54 * \\
(0.24)\end{array}$ & $\begin{array}{l}0.47 \dagger \\
(0.24)\end{array}$ & $\begin{array}{l}0.2 \\
(0.27)\end{array}$ & $\begin{array}{l}0.25 \\
(0.26)\end{array}$ & $\begin{array}{l}0.55^{*} \\
(0.19)\end{array}$ \\
\hline & Food & $\begin{array}{l}1.41 * * * \\
(0.22)\end{array}$ & $\begin{array}{l}0.86 \text { *** } \\
(0.23)\end{array}$ & $\begin{array}{l}0.27 \\
(0.23)\end{array}$ & $\begin{array}{l}0.35 \\
(0.26)\end{array}$ & $\begin{array}{l}0.52^{*} \\
(0.26)\end{array}$ & $\begin{array}{l}0.76^{* * * *} \\
(0.18)\end{array}$ \\
\hline & Clothes & $\begin{array}{l}0.99 * * * \\
(0.25)\end{array}$ & $\begin{array}{l}0.31 \\
(0.26)\end{array}$ & $\begin{array}{l}0.04 \\
(0.26)\end{array}$ & $\begin{array}{l}-0.03 \\
(0.28)\end{array}$ & $\begin{array}{l}0.36 \\
(0.28)\end{array}$ & $\begin{array}{l}0.34 \\
(0.2)\end{array}$ \\
\hline & Transit & $\begin{array}{l}0.49 * \\
(0.21)\end{array}$ & $\begin{array}{l}0.47 * \\
(0.22)\end{array}$ & $\begin{array}{l}0.31 \\
(0.23)\end{array}$ & $\begin{array}{l}0.46 \dagger \\
(0.25)\end{array}$ & $\begin{array}{l}0.73 * * \\
(0.25)\end{array}$ & $\begin{array}{l}0.46^{*} \\
(0.16)\end{array}$ \\
\hline & Temptation Goods & $\begin{array}{l}0.06 \\
(0.22)\end{array}$ & $\begin{array}{l}0.33 \\
(0.22)\end{array}$ & $\begin{array}{l}0.05 \\
(0.23)\end{array}$ & $\begin{array}{l}-0.4 \\
(0.26)\end{array}$ & $\begin{array}{l}-0.14 \\
(0.25)\end{array}$ & $\begin{array}{l}0.03 \\
(0.17)\end{array}$ \\
\hline & Other (e.g., bills) & $\begin{array}{l}-0.01 \\
(0.26)\end{array}$ & $\begin{array}{l}0.11 \\
(0.27)\end{array}$ & $\begin{array}{l}-0.08 \\
(0.28)\end{array}$ & $\begin{array}{l}0 \\
(0.3)\end{array}$ & $\begin{array}{l}0.13 \\
(0.3)\end{array}$ & $\begin{array}{l}0.02 \\
(0.2)\end{array}$ \\
\hline \multicolumn{8}{|c|}{ Food Security } \\
\hline & Food Security & $\begin{array}{l}0.46^{*} \\
(0.22)\end{array}$ & $\begin{array}{l}-0.1 \\
(0.22)\end{array}$ & $\begin{array}{l}-0.11 \\
(0.23)\end{array}$ & $\begin{array}{l}-0.33 \\
(0.25)\end{array}$ & $\begin{array}{l}0.02 \\
(0.25)\end{array}$ & $\begin{array}{l}0.04 \\
(0.17)\end{array}$ \\
\hline \multicolumn{8}{|c|}{ Employment } \\
\hline & Weekly Job Hours & $\begin{array}{l}0.07 \\
(0.2)\end{array}$ & $\begin{array}{l}0.05 \\
(0.21)\end{array}$ & $\begin{array}{l}0.1 \\
(0.21)\end{array}$ & $\begin{array}{l}0.09 \\
(0.24)\end{array}$ & $\begin{array}{l}-0.02 \\
(0.24)\end{array}$ & $\begin{array}{l}0.07 \\
(0.16)\end{array}$ \\
\hline & Hourly Pay & $\begin{array}{l}-0.06 \\
(0.22)\end{array}$ & $\begin{array}{l}0.31 \\
(0.23)\end{array}$ & $\begin{array}{l}-0.03 \\
(0.24)\end{array}$ & $\begin{array}{l}0.04 \\
(0.26)\end{array}$ & $\begin{array}{l}0.02 \\
(0.26)\end{array}$ & $\begin{array}{l}0.08 \\
(0.18)\end{array}$ \\
\hline \multicolumn{8}{|c|}{ Education } \\
\hline & Weekly Course Hours & - & $\begin{array}{l}0.06 \\
(0.3)\end{array}$ & $\begin{array}{l}-0.34 \\
(0.3)\end{array}$ & $\begin{array}{l}0.04 \\
(0.32)\end{array}$ & $\begin{array}{l}-0.47 \\
(0.33)\end{array}$ & $\begin{array}{l}-0.17 \\
(0.23)\end{array}$ \\
\hline \multicolumn{8}{|c|}{ Cognitive Functioning } \\
\hline & Executive Function Accuracy & $\begin{array}{l}0.12 \\
(0.29)\end{array}$ & $\begin{array}{l}0.63^{*} \\
(0.28)\end{array}$ & $\begin{array}{l}0.26 \\
(0.3)\end{array}$ & $\begin{array}{l}0.09 \\
(0.33)\end{array}$ & $\begin{array}{l}-0.15 \\
(0.35)\end{array}$ & $\begin{array}{l}0.27 \\
(0.22)\end{array}$ \\
\hline & Fluid Intelligence Accuracy & $\begin{array}{l}-0.22 \\
(0.17)\end{array}$ & $\begin{array}{l}-0.26 \\
(0.18)\end{array}$ & $\begin{array}{l}-0.22 \\
(0.19)\end{array}$ & $\begin{array}{l}0.23 \\
(0.22)\end{array}$ & $\begin{array}{l}-0.12 \\
(0.22)\end{array}$ & $\begin{array}{l}-0.15 \\
(0.13)\end{array}$ \\
\hline \multicolumn{8}{|c|}{ Subjective Well-being } \\
\hline & Satisfaction with Life & $\begin{array}{l}0.17 \\
(0.17)\end{array}$ & $\begin{array}{l}0.14 \\
(0.17)\end{array}$ & $\begin{array}{l}-0.05 \\
(0.18)\end{array}$ & $\begin{array}{l}-0.04 \\
(0.2)\end{array}$ & $\begin{array}{l}0.21 \\
(0.2)\end{array}$ & $\begin{array}{l}0.12 \\
(0.13)\end{array}$ \\
\hline & Positive Affect & $\begin{array}{l}0.45^{*} \\
(0.2)\end{array}$ & $\begin{array}{l}0.11 \\
(0.2)\end{array}$ & $\begin{array}{l}-0.08 \\
(0.21)\end{array}$ & $\begin{array}{l}0.06 \\
(0.23)\end{array}$ & $\begin{array}{l}0.3 \\
(0.23)\end{array}$ & $\begin{array}{l}0.2 \\
(0.16)\end{array}$ \\
\hline & Negative Affect & $\begin{array}{l}-0.24 \\
(0.18)\end{array}$ & $\begin{array}{l}-0.04 \\
(0.19)\end{array}$ & $\begin{array}{l}0.08 \\
(0.19)\end{array}$ & $\begin{array}{l}-0.03 \\
(0.21)\end{array}$ & $\begin{array}{l}-0.24 \\
(0.21)\end{array}$ & $\begin{array}{l}-0.1 \\
(0.14)\end{array}$ \\
\hline & Meaning in Life & $\begin{array}{l}0.11 \\
(0.19)\end{array}$ & $\begin{array}{l}-0.17 \\
(0.19)\end{array}$ & $\begin{array}{l}-0.34 \dagger \\
(0.2)\end{array}$ & $\begin{array}{l}-0.34 \\
(0.22)\end{array}$ & $\begin{array}{l}0.14 \\
(0.22)\end{array}$ & $\begin{array}{l}-0.09 \\
(0.15)\end{array}$ \\
\hline & Social Connectedness & $\begin{array}{l}0.03 \\
(0.16)\end{array}$ & $\begin{array}{l}-0.19 \\
(0.17)\end{array}$ & $\begin{array}{l}-0.3 \dagger \\
(0.17)\end{array}$ & $\begin{array}{c}-0.38^{*} \\
(0.19)\end{array}$ & $\begin{array}{l}-0.21 \\
(0.19)\end{array}$ & $\begin{array}{l}-0.17 \\
(0.13)\end{array}$ \\
\hline & Frequency Seeing Confidante & $\begin{array}{l}0.02 \\
(0.22)\end{array}$ & $\begin{array}{l}0.19 \\
(0.23)\end{array}$ & $\begin{array}{l}-0.08 \\
(0.24)\end{array}$ & $\begin{array}{l}0.13 \\
(0.26)\end{array}$ & $\begin{array}{l}0.26 \\
(0.26)\end{array}$ & $\begin{array}{l}0.09 \\
(0.17)\end{array}$ \\
\hline & Self-Efficacy & $\begin{array}{l}0.1 \\
(0.17)\end{array}$ & $\begin{array}{l}0.03 \\
(0.18)\end{array}$ & $\begin{array}{l}0.14 \\
(0.18)\end{array}$ & $\begin{array}{l}0.13 \\
(0.2)\end{array}$ & $\begin{array}{l}0 \\
(0.2)\end{array}$ & $\begin{array}{l}0.09 \\
(0.13)\end{array}$ \\
\hline & Empowerment & $\begin{array}{l}0.04 \\
(0.21)\end{array}$ & $\begin{array}{l}-0.02 \\
(0.22)\end{array}$ & $\begin{array}{l}-0.09 \\
(0.23)\end{array}$ & $\begin{array}{l}-0.26 \\
(0.25)\end{array}$ & $\begin{array}{l}-0.12 \\
(0.25)\end{array}$ & $\begin{array}{l}-0.04 \\
(0.17)\end{array}$ \\
\hline & Quality of Life - Global & - & $\begin{array}{l}-0.15 \\
(0.2)\end{array}$ & $\begin{array}{l}-0.12 \\
(0.2)\end{array}$ & $\begin{array}{l}0.02 \\
(0.22)\end{array}$ & $\begin{array}{l}0.01 \\
(0.22)\end{array}$ & $\begin{array}{l}-0.07 \\
(0.15)\end{array}$ \\
\hline & Psychiatric Symptomatology & - & $\begin{array}{l}0 \\
(0.19)\end{array}$ & - & - & $\begin{array}{l}0.01 \\
(0.22)\end{array}$ & $\begin{array}{l}0 \\
(0.17)\end{array}$ \\
\hline
\end{tabular}




\begin{tabular}{|c|c|c|c|c|c|c|c|}
\hline Domain & Outcome & $1 \mathrm{~m}$ & $3 \mathrm{~m}$ & $6 \mathrm{~m}$ & $9 \mathrm{~m}$ & $12 \mathrm{~m}$ & Overall \\
\hline \multicolumn{8}{|c|}{ Substance Use } \\
\hline & Alcohol Use Severity & - & $\begin{array}{l}0.19 \\
(0.2)\end{array}$ & - & - & $\begin{array}{l}-0.11 \\
(0.22)\end{array}$ & $\begin{array}{l}0.07 \\
(0.17)\end{array}$ \\
\hline & Substance Use Severity & - & $\begin{array}{c}-0.33 \dagger \\
(0.19)\end{array}$ & - & - & $\begin{array}{l}-0.34 \\
(0.22)\end{array}$ & $\begin{array}{l}-0.34 \\
(0.16)\end{array}$ \\
\hline \multicolumn{8}{|c|}{ Service Use } \\
\hline & Cost of All Service Use & - & $\begin{array}{l}-0.76^{* * *} \\
(0.24)\end{array}$ & $\begin{array}{c}-0.46 \dagger \\
(0.24)\end{array}$ & $\begin{array}{l}-0.5 \dagger \\
(0.26)\end{array}$ & $\begin{array}{l}-0.3 \\
(0.27)\end{array}$ & $\begin{array}{l}-0.55^{*} \\
(0.19)\end{array}$ \\
\hline & Cost of Shelter Use & - & $\begin{array}{l}-0.92 * * * \\
(0.23)\end{array}$ & $\begin{array}{l}-0.53^{*} \\
(0.23)\end{array}$ & $\begin{array}{c}-0.46 \dagger \\
(0.25)\end{array}$ & $\begin{array}{l}-0.36 \\
(0.25)\end{array}$ & $\begin{array}{l}-0.62 * \\
(0.19)\end{array}$ \\
\hline
\end{tabular}

Notes. Some outcomes were not measured at all time points.

\section{Public Prediction of Spending on Temptation Goods}

Despite the benefits observed in the RCT, there are social barriers that may prevent cash transfers from being adopted as a public policy. In particular, research suggests that people experiencing homelessness are perceived as having less interpersonal warmth and competence (23) and less important psychological needs than others (24). This dehumanizing bias, and the perceived risk spending money on temptation goods (25), can favor the provision of paternalistic forms of aid over more agentic forms of aid (26). To understand any bias toward the homeless population, we explored public predictions of spending behavior of cash transfer recipients who are homeless.

The next experiment utilized a nationally representative sample $(N=1,114)$ on Amazon Mechanical Turk, where online participants read a vignette describing someone who was given an unconditional cash transfer of $\$ 7,500$ and then predicted the recipient's expenditures across various spending categories (e.g., rent, clothing, alcohol, drugs) over one year. The category of interest was temptation goods. Using a $2 \times 2$ between-subjects factorial design, we varied the identity of the recipient (other vs. self) and housing status (homeless vs. non-homeless). This design allowed us to test if any biases are associated with being homeless, being another person, or specifically being a homeless-other. In all conditions, we specified that the recipient was at a low risk of mental health challenges or problematic substance use, to be comparable to the participant sample in the RCT. Detailed methods and results are provided in Supplementary Materials.

In line with our pre-registered hypothesis, we found that the predicted spending on temptation goods was significantly higher $(M=\$ 329, S D=5.52)$ when the recipient was described as a homeless other (i.e., someone who is homeless), compared to when the recipient was described as a non-homeless individual or as the participants themselves whether homeless or $\operatorname{not}(M=\$ 182, S D=404, t(1094)=4.74, p<.001, d=0.33,95 \%$ CI $[.19, .47]$, see Figure 2$)$.

Bonferroni-corrected pairwise comparisons between the homeless other condition and each of the other three conditions were all significant $\left(p^{\prime} s<.001, d\right.$ 's $\left.>.30\right)$. This reveals a public mistrust of individuals experiencing homelessness in their ability to manage money. This mistrust could be a barrier for establishing cash transfers as a homelessness reduction policy. 


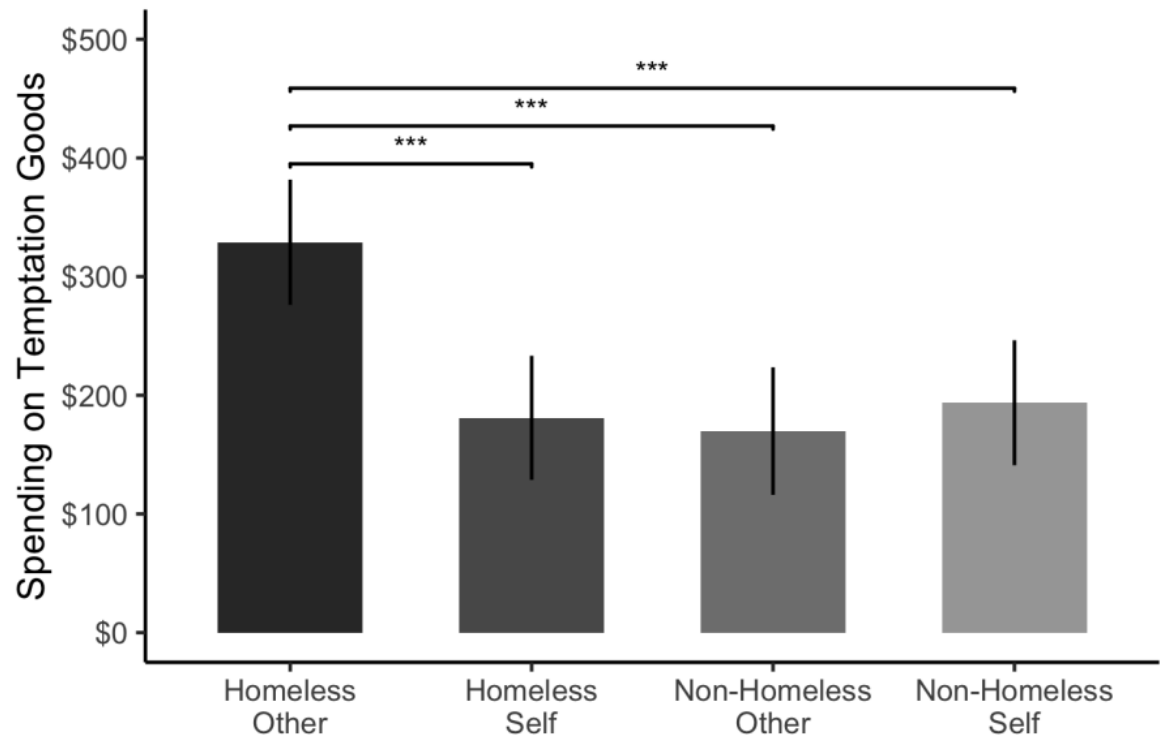

Figure 2. Predicted spending on temptation goods (alcohol, drugs, cigarettes) was higher in the homeless other condition than the other conditions. Error bars represent $95 \%$ confidence intervals. $(* * * p<.001)$.

\section{Public Support for Cash Transfer Policy}

To examine how a government policy delivering cash transfers to homeless individuals might be received by the public, we conducted a final experiment with another nationally representative sample $(N=1,373)$ from Amazon Mechanical Turk. In this experiment, we presented the findings from the cash transfer study on housing stability and spending on temptation goods to examine whether these findings would influence public support for the cash transfer policy. Specifically, participants were assigned to one of three conditions. In the counterstereotype condition, participants first read a summary of a study that distributed a $\$ 7,500$ cash transfer to homeless individuals without severe levels of substance use, alcohol use, or mental health challenges, and a summary of the results that the cash transfer resulted in decreased spending on alcohol, drugs, and cigarettes and increased spending on rent, food, and clothing. In the utilitarian condition, participants read the same summary except results showed that cash recipients reduced their reliance on the shelter system and saved more money than the cash transfer itself, producing net savings for society. In the control condition, participants did not read a summary of the study or results. Participants in all conditions then rated their level of support for a public policy that distributes $\$ 7,500$ to people who are homeless and do not have a severe level of substance use, alcohol use, or mental health challenges.

In line with our pre-registered hypothesis, support for the public policy was significantly higher in the utilitarian condition $(M=3.95, S D=1.06, t(875)=5.83, p<.001, d=0.38,95 \% \mathrm{CI}[.25$, $.51])$ or in the counter-stereotype condition $(M=3.78, S D=1.24, t(896)=3.4, p=.002, d=0.22$, $95 \% \mathrm{CI}[.09, .36])$ than the control condition $(M=3.50, S D=1.3$, see Figure 3$)$, with a marginal difference between the counter-stereotype and utilitarian conditions $(t(872)=2.23, p=.077$; all $p$ values were Bonferroni-corrected). This suggests that support for a cash transfer policy is strengthened by counteracting the stereotype that individuals experiencing homelessness would increase spending on temptation goods, or by providing the utilitarian evidence that the cash transfer generated positive impact on the recipients and also net savings for society. These two 
messages can be used to boost public support for a future cash transfer policy to combat homelessness.

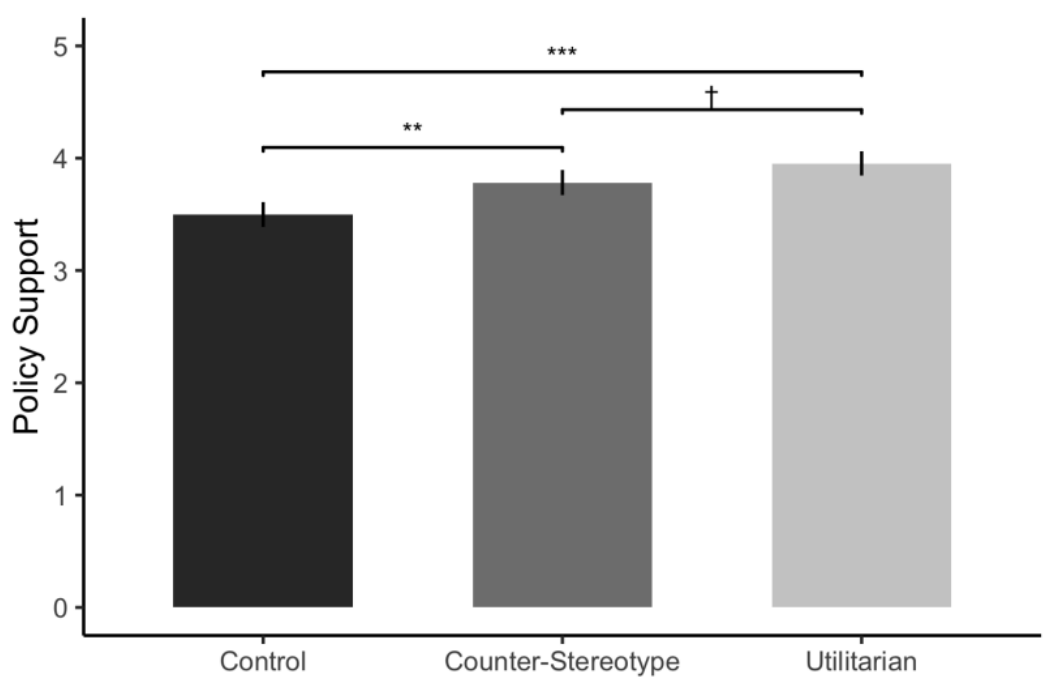

Figure 3. Policy support was significantly higher in the counter-stereotype condition or the utilitarian condition than the control condition. Error bars represent $95 \%$ confidence intervals. $(\dagger p<.1, * * p<.01$, $* * * p<.001)$

The current findings from three experiments provide a number of important implications for policy. First, our work suggests that cash transfers may offer a novel, cost-effective, and flexible solution to combat homelessness for recently homeless individuals without severe substance use, alcohol use, or psychiatric symptoms. Building upon existing social supports, this approach may propel individuals to move beyond homelessness by providing choice and the ability to meet their own needs. While cash transfers are not a panacea, they may speed the path to stability and can be integrated easily with existing supports. Second, our study adds to growing global evidence demonstrating the benefits of cash transfers on low-income populations $(27,28)$. By demonstrating impact for reducing homelessness, this work and opens new avenues for research with other marginalized groups (e.g., youth aging out of foster care, people exiting prisons) and other types of transfers (e.g., \$10k, guaranteed income). Finally, the second experiment highlighted how cash transfer policies may face resistance from the public due to people's mistrust in recipient spending on temptation goods. To reduce the resistance, policy support can be bolstered by showing counter-stereotypical or utilitarian benefits of the cash transfer, as shown in the final experiment. Thus, the current findings provide useful guidelines on garnering public support for policies that aim to raise the income floor for the homeless population. While the RCT results are preliminary and need to be replicated with additional high-powered confirmatory research, this study provides proof of concept for the provision of cash assistance for recently homeless individuals. As over 100 countries around the world have embraced cash assistance to help individuals cope with economic hardships due to COVID-19, the time has never been better to extend these benefits for those most in need. 


\section{References:}

1. UN Habitat, "World Cities Report 2020: The value of sustainable urbanization" (Nairobi, Kenya, 2020).

2. M. Ridley, G. Rao, F. Schilbach, V. Patel, Poverty, depression, and anxiety: Causal evidence and mechanisms. Science (80-. ). 370 (2020), doi:10.1126/science.aay0214.

3. S. Fazel, J. R. Geddes, M. Kushel, The health of homeless people in high-income countries: Descriptive epidemiology, health consequences, and clinical and policy recommendations. Lancet. 384, 1529-1540 (2014).

4. S. W. Hwang, R. Wilkins, M. Tjepkema, P. J. O’Campo, J. R. Dunn, Mortality among residents of shelters, rooming houses, and hotels in Canada: 11 Year follow-up study. BMJ. 339, 1068 (2009).

5. E. A. Latimer, D. Rabouin, Z. Cao, A. Ly, G. Powell, T. Aubry, J. Distasio, S. W. Hwang, J. M. Somers, V. Stergiopoulos, S. Veldhuizen, E. E. M. Moodie, A. Lesage, P. N. Goering, Costs of services for homeless people with mental illness in 5 Canadian cities: A large prospective follow-up study. C. Open. 5, E576-E585 (2017).

6. D. Flaming, H. Toros, P. Burns, "Home not found: The cost of homelessness in Silicon Valley" (2015), (available at http://www.economicrt.org).

7. W. N. Evans, J. X. Sullivan, M. Wallskog, The impact of homelessness prevention programs on homelessness. Science (80-. ). 353, 694-699 (2016).

8. R. Rosenheck, in How to House the Homeless, I. G. Ellen, B. O'Flaherty, Eds. (New York: Russell Sage Foundation, 2010), pp. 17-36.

9. V. Stergiopoulos, S. W. Hwang, A. Gozdzik, R. Nisenbaum, E. Latimer, D. Rabouin, C. E. Adair, J. Bourque, J. Connelly, J. Frankish, L. Y. Katz, K. Mason, V. Misir, K. O’Brien, J. Sareen, C. G. Schütz, A. Singer, D. L. Streiner, H.-M. Vasiliadis, P. N. Goering, Effect of scattered-site housing using rent supplements and intensive case management on housing stability among homeless adults with mental illness. JAMA. 313 (2015), doi:10.1001/jama.2015.1163.

10. B. O'Flaherty, Homelessness research: A guide for economists (and friends). J. Hous. Econ. 44, 1-25 (2019).

11. S. Handa, A. Peterman, C. Huang, C. Halpern, A. Pettifor, H. Thirumurthy, Impact of the Kenya Cash Transfer for Orphans and Vulnerable Children on early pregnancy and marriage of adolescent girls. Soc. Sci. Med. 141, 36-45 (2015).

12. J. Haushofer, J. Shapiro, The Short-term Impact of Unconditional Cash Transfers to the Poor: Experimental Evidence from Kenya. Q. J. Econ. 131, 1973-2042 (2016).

13. K. Kilburn, H. Thirumurthy, C. T. Halpern, A. Pettifor, S. Handa, Effects of a large-scale unconditional cash transfer program on mental health outcomes of young people in Kenya. J. Adolesc. Heal. 58, 223-229 (2016).

14. L. Hjelm, S. Handa, J. de Hoop, T. Palermo, Poverty and perceived stress: Evidence from two unconditional cash transfer programs in Zambia. Soc. Sci. Med. 177, 110-117 (2017).

15. BC Non-Profit Housing Association, "2020 Homeless Count in Metro Vancouver" (Vancouver, 2020), (available at 
https://www.vancitycommunityfoundation.ca/initiatives/2020-homeless-count).

16. D. Staley, N. El-Guebaly, Psychometric properties of the drug abuse screening test in a psychiatric patient population. Addict. Behav. 15, 257-264 (1990).

17. J. B. Saunders, O. G. Aasland, T. F. Babor, J. R. De La Fuente, M. Grant, Development of the Alcohol Use Disorders Identification Test (AUDIT): WHO Collaborative Project on Early Detection of Persons with Harmful Alcohol Consumption-II. Addiction. 88, 791804 (1993).

18. D. L. Shern, N. Z. Wilson, A. S. Coen, D. C. Patrick, M. Foster, D. A. Bartsch, J. Demmler, Client Outcomes II: Longitudinal Client Data from the Colorado Treatment Outcome Study. Milbank Q. 72, 123 (1994).

19. Y. Benjamini, Y. Hochberg, Controlling the False Discovery Rate: A Practical and Powerful Approach to Multiple Testing. J. R. Stat. Soc. Ser. B. 57, 289-300 (1995).

20. D. K. Evans, A. Popova, Cash Transfers and Temptation Goods. Econ. Dev. Cult. Change. 65, 189-221 (2017).

21. R. Kuhn, D. P. Culhane, Applying cluster analysis to test a typology of homelessness by pattern of shelter utilization: Results from the analysis of administrative data. Am.J. Community Psychol. 26, 207-232 (1998).

22. A. Segaert, A. Bauer, T. Craddock, P.-P. Lacroix, J. Rivier, B. Skelton, “The national shelter study 2005-2014: Emergency shelter use in Canada" (2017).

23. S. T. Fiske, A. J. C. Cuddy, P. Glick, Universal dimensions of social cognition: warmth and competence. Trends Cogn. Sci. 11, 77-83 (2007).

24. J. Schroeder, N. Epley, Demeaning: Dehumanizing Others by Minimizing the Importance of Their Psychological Needs. J. Pers. Soc. Psychol. (2020), doi:10.1037/pspa0000199.

25. T. Talbot, M. Collin, "Using Aid for Cash Transfers: What Do 10,000 People in 28 Countries Think?” (2016), (available at https://www.cgdev.org/blog/what-do-10000people-28-countries-think-using-aid-cash-transfers).

26. J. Schroeder, A. Waytz, N. Epley, Endorsing Help For Others That You Oppose For Yourself: Mind Perception Alters the Perceived Effectiveness of Paternalism. J. Exp. Psychol. Gen. 146, 1106-1125 (2017).

27. M. Sulaiman, N. Goldberg, D. Karlan, A. de Montesquiou, Eliminating Extreme Poverty: Comparing the Cost-Effectiveness of Livelihood, Cash Transfer, and Graduation Approaches. Access to Financ. Forum. Reports by CGAP Its Partners. 11 (2016).

28. F. Bastagli, J. Hagen-Zanker, L. Harman, V. Barca, G. Sturge, T. Schmidt, L. Pellerano, "Cash transfers: what does the evidence say? A rigorous review of programme impact and the role of design and implementation features." (London, 2016), (available at https://odi.org/en/publications/cash-transfers-what-does-the-evidence-say-a-rigorousreview-of-impacts-and-the-role-of-design-and-implementation-features/).

29. C. C. Hall, J. Zhao, E. Shafir, Self-Affirmation Among the Poor: Cognitive and Behavioral Implications. Psychol. Sci. 25, 619-625 (2014).

30. S. Tsemberis, G. McHugo, V. Williams, P. Hanrahan, A. Srefancic, Measuring homelessness and residential stability: the residential time-line follow-back inventory. $J$. 
Community Psychol. 35, 29-42 (2007).

31. E. A. Latimer, T. Lecomte, D. R. Becker, R. E. Drake, I. Duclose, N. L. Piat, M.-S. StPierre, X. Haiyi, Generalisability of the individual placement and support model of supported employment. Br. J. Psychiatry. 189, 65-73 (2006).

32. A. Mani, S. Mullainathan, E. Shafir, J. Zhao, Poverty impedes cognitive function. Science (80-. ). 341, 976-980 (2013).

33. M. C. Davidson, D. Amso, L. C. Anderson, A. Diamond, Development of cognitive control and executive functions from 4 to 13 years: Evidence from manipulations of memory, inhibition, and task switching. Neuropsychologia. 44, 2037-2078 (2006).

34. J. Raven, Raven Manual for Raven's Progressive Matrices and Mill Hill Vocabulary Scales (Oxford Psychologists Press, Oxford, 1981).

35. E. Diener, R. A. Emmons, R. J. Larsen, S. Griffin, The satisfaction with life scale. J. Pers. Assess. 49, 71-75 (1985).

36. E. Diener, D. Wirtz, R. Biswas-Diener, W. Tov, C. Kim-Prieto, D. Choi, S. Oishi, in Assessing Well-Being: The Collected Works of Ed Diener, E. Diener, Ed. (Springer Netherlands, Dordrecht, 2009;), pp. 247-266.

37. A. F. Lehman, Measures of quality of life among persons with severe and persistent mental disorders. Soc. Psychiatry Psychiatr. Epidemiol. 31, 78-88 (1996).

38. R. M. Lee, M. Draper, S. Lee, Social connectedness, dysfunctional interpersonal behaviors, and psychological distress: Testing a mediator model. J. Couns. Psychol. 48, 310-318 (2001).

39. C. Pankratz, G. Nelson, M. Morrison, A quasi-experimental evaluation of rent assistance for individuals experiencing chronic homelessness. J. Community Psychol. 45, 1065-1079 (2017).

40. R. Schwarzer, M. Jerusalem, in Measures in health psychology: A user's portfolio. Causal and control beliefs, J. Weinman, S. Wright, M. Johnston, Eds. (NFER-NELSON, Windsor, UK, 1995), pp. 35-37.

41. S. P. Segal, C. Silverman, T. Temkin, Measuring empowerment in client-run self-help agencies. Community Ment. Health J. 31, 215-227 (1995).

42. USDA, "U.S. Adult Food Security Survey Module: Three-stage design, with screeners, 2012" (2012), (available at

http://www.ers.usda.gov/datafiles/Food_Security_in_the_United_States/Food_Security_S urvey_Modules/ad2012.pdf)

43. P. N. Goering, D. L. Streiner, C. Adair, T. Aubry, J. Barker, J. Distasio, S. W. Hwang, J. Komaroff, E. Latimer, J. Somers, D. M. Zabkiewicz, The at Home/Chez Soi trial protocol: A pragmatic, multi-site, randomised controlled trial of a Housing First intervention for homeless individuals with mental illness in five Canadian cities. BMJ Open. 1, 1-18 (2011).

44. J. E. Ware, M. M. A. Kosinski, S. D. Keller, A 12-Item Short-Form Health Survey: Construction of Scales and Preliminary Tests of Reliability and Validity. Med. Care. 34, 220-233 (1996). 
Acknowledgments: We would like to thank (in alphabetical order) Kirstin Appelt, Heather Hay, Johannes Haushofer, Vince Hopkins, Stephen Hwang, Supreet Kaur, Anandi Mani, Paul Niehaus, Oanh Nguyen, Dan O’Flaherty, Ong Qiyan, Lindsey Richardson, Jason Rights, Frank Schilbach, Eldar Shafir, Anuj Shah, Dilip Soman, Rob Turnbull, and many others for giving instrumental, constructive, and helpful feedback on the study design, statistical analyses, and the manuscript. We would like to thank excellent assistance with data collection and literature review from Alice Hopkins, Hani Lee, Anna Balsevich, Mark Ellis, Courtney Pankratz, Brandon Tomm, Kenneth Ong, Julie McGuiness, Rose Buhl, David Ramsey, Annemarie Goytan, Victor Lee, Katen Jolly, Carrie Siggins, Paisley McHaffie, Sarah Eisler, Kim Gray, Trevor Gray, Whitney MacRae, Sandy Rogers, Katelon Starre, Andrae Cockett, Rie Yasumiishi, and Anya Fineman.

\section{Funding:}

Employment and Social Development Canada grant \#1442779 (CW, JZ)

McConnell Foundation grant (CW, JZ)

Catherine Donnelly Foundation grant $(\mathrm{CW}, \mathrm{JZ})$

Power to Give Foundation grant (CW, JZ)

National Science Foundation grant SUB0000108 (JZ)

Sloan Foundation grant SUB0000054 (JZ)

Vanier Scholarship (RD)

\section{Author contributions:}

Authors names are listed alphabetically.

Conceptualization: RD, CW, JZ

Methodology: RD, AP, CW, JZ

Investigation: RD, AP, JZ

Visualization: RD, JZ

Funding acquisition: $\mathrm{CW}, \mathrm{JZ}$

Project administration: RD, CW, JZ

Supervision: JZ, CW, AP

Writing - original draft: RD, JZ

Writing - review \& editing: RD, AP, JZ

Competing interests: JZ was on the NLP board of directors from 2016 to 2020.

\section{Data and materials availability:}

Pre-registrations are available on the Open Science Framework. To protect participant privacy, data are not publicly available but will be made available upon reviewer request.

RCT Original preregistration: https://osf.io/e68ab

RCT update to preregistration: https://osf.io/h3u9k

Study 2 preregistration:

https://osf.io/86x9z?view_only=c364b6f934ab4e2eb77e7fa342c83930

Study 2 replication preregistration:

https://osf.io/txqgv/?view_only=ffe5355f5b2347f9a8e9177446d8d72a

Study 3 preregistration:

https://osf.io/resf3/?view_only=a3181257a92b4608a326e0ebf2d41e17 
Study 3 replication preregistration:

https://osf.io/3876c/?view_only=2afe9629a1c048e8b37d27b6a6852e0d

Study 2 and Study 3 data:

https://osf.io/kdn4j/?view_only=511852ce5b434960b20591ac650f3de8 


\section{Supplementary Materials for}

Unconditional cash transfers reduce homelessness

Ryan Dwyer, Anita Palepu, Claire Williams, Jiaying Zhao

Correspondence to: jiayingz@psych.ubc.ca 


\section{Cash Transfer Experiment}

\subsection{Participants}

\subsubsection{Preregistered Power Analysis}

The experiment was pre-registered at osf.io/e68ab and a minor update was provided at osf.io/h3u $9 \mathrm{k}$. Previous research has found that the estimated effect of cash transfers on psychological well-being is $d=0.26$ (12). We conducted a power analysis for a mixed ANOVA with an effect size of 0.26 (i.e., $f=.13$ ), power $=0.80$, alpha $=0.05$, and a correlation between repeated measures $r=.60$, which suggested that we would need a minimum total of 96 participants to detect an interaction between groups (48 per group). To obtain our target sample, we conducted four waves of recruitment from shelters. Participants who passed the screening criteria were successfully enrolled into the study based on the following criteria. In the cash group, all participants who received the cash transfer $(n=50)$ were included in the analysis. In the control group, participants were only included if they completed at least one follow-up survey $(n=65)$. This may have introduced a self-selection bias that favored more conscientious or higher functioning participants in the control group. We recruited more control participants to account for a possible higher attrition rate in the control group.

\subsubsection{Demographics}

Participant demographics of the cash and control groups are presented in Table S1.

Demographics were mostly balanced across the two groups, except that more cash participants had children, and cash participants had been homeless for longer.

Table S1. Demographic information by group and balance check.

\begin{tabular}{lllll}
\hline Demographics & Control & Cash & Total & $p$ \\
\hline Age & 40.7 & 43.4 & 41.9 & 0.274 \\
Born in Canada & $86.2 \%$ & $78.0 \%$ & $82.6 \%$ & 0.371 \\
Children Yes & $23.0 \%$ & $55.3 \%$ & $37.0 \%$ & 0.001 \\
Number of Children & 0.4 & 1 & 0.6 & 0.002 \\
Female & $35.4 \%$ & $46.0 \%$ & $40.0 \%$ & 0.337 \\
Marital Status Single & $58.5 \%$ & $54.0 \%$ & $56.5 \%$ & 0.773 \\
Government ID Yes & $71.9 \%$ & $82.0 \%$ & $76.3 \%$ & 0.298 \\
First Experience Homeless Yes & $40.0 \%$ & $56.0 \%$ & $47.0 \%$ & 0.130 \\
Homelessness Duration (weeks) & 21.3 & 30.3 & 25.2 & 0.030
\end{tabular}




$\begin{array}{lllll}\text { Number of Times Homeless } & 2.7 & 3.1 & 2.9 & 0.778 \\ \text { Total Time Homeless (Years) } & 1.7 & 1.8 & 1.7 & 0.795 \\ \text { Annual Income at Screening } & 11985.9 & 13279.1 & 12579.7 & 0.588 \\ \text { Total Annual Spending at Baseline } & 13007.6 & 10106.8 & 11772.1 & 0.134 \\ \text { Employed at Screening Yes } & 29.0 \% & 28.6 \% & 28.8 \% & 1.000 \\ \text { Would Like a Job Yes } & 91.8 \% & 95.1 \% & 93.3 \% & 0.843 \\ \text { Receiving Income Assistance Yes } & 47.7 \% & 58.0 \% & 52.2 \% & 0.364 \\ \text { Receiving Disability Assistance Yes } & 27.7 \% & 34.0 \% & 30.4 \% & 0.600 \\ \text { Mental Health Diagnosis Yes } & 40.6 \% & 46.9 \% & 43.4 \% & 0.631 \\ \text { Substance Dependence Disorder Yes } & 9.4 \% & 18.0 \% & 13.2 \% & 0.283\end{array}$

Notes. Balance tests were conducted using $t$-tests for numeric variables and chi-square tests for categorical variables. $P$ values are not corrected for multiple comparisons. 


\subsubsection{Reasons for Homelessness}

At the screening survey, participants were asked to describe what caused their current episode of homelessness. These responses were then categorized by common themes and coded by the research team. The most common themes are presented in Figure S1. Lack of money was the second most frequent reason that participants described.

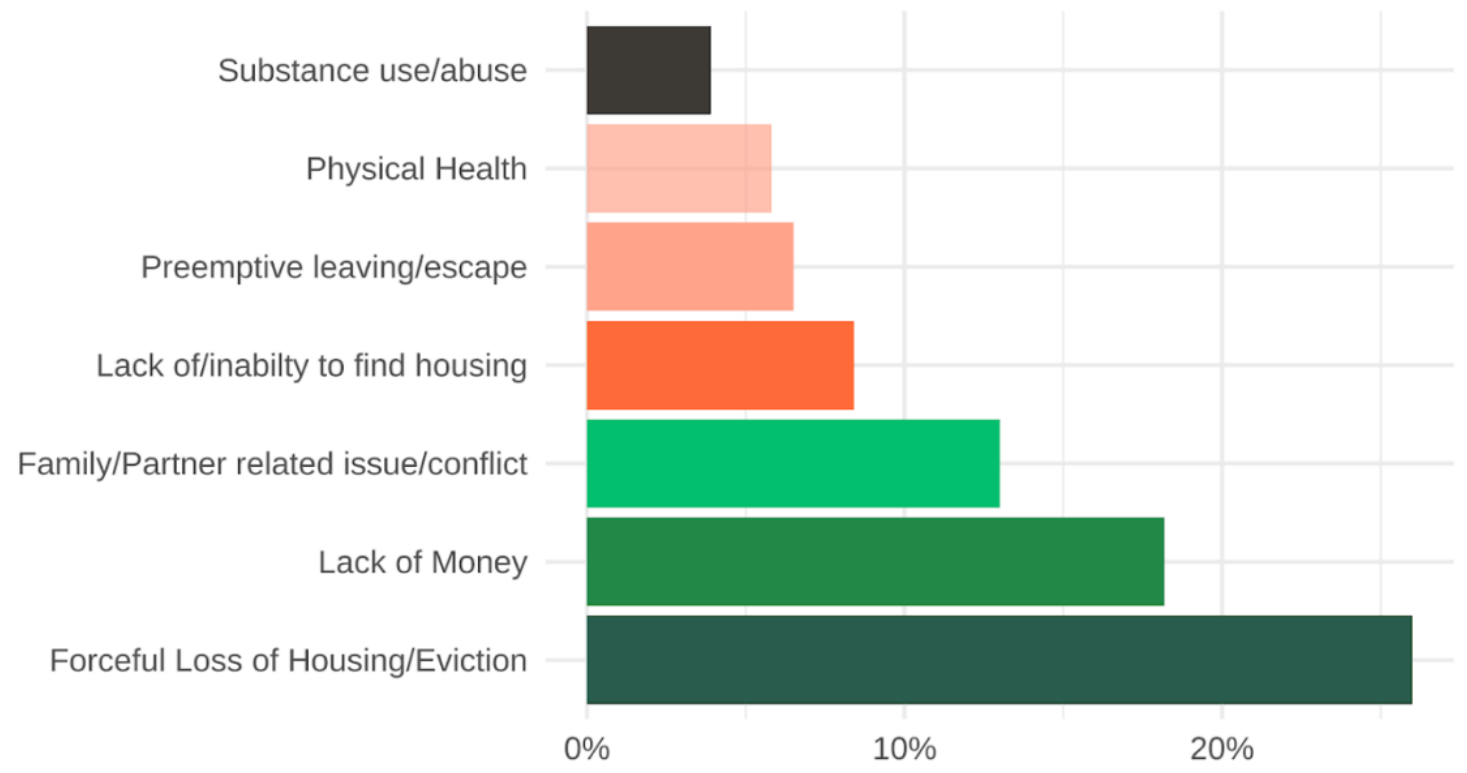

Figure S1. Reasons contributing to most recent experience of homelessness. 


\subsection{Stimuli and Procedure}

\subsubsection{Inclusion Criteria for Screening}

There were three inclusion criteria: age between 19 and 65, the most recent episode of homelessness must have started within the last two years, and the participant must be a Canadian citizen or permanent resident.

\subsubsection{Exclusion Criteria for Screening}

To reduce potential risks of harm (e.g. overdose) from the cash transfer, we excluded participants with severe levels of substance use, alcohol use, and mental health symptoms. The screening tools and thresholds are presented in Table S2.

Table S2. Exclusion criteria.

\begin{tabular}{lll}
\hline Criteria & Screening Tool & Threshold \\
\hline $\begin{array}{l}\text { Substance } \\
\text { use severity }\end{array}$ & $\begin{array}{l}\text { Drug Abuse Screening Test } \\
\text { (DAST-10) (16) }\end{array}$ & Any score $\geq 6$ \\
$\begin{array}{l}\text { Alcohol use } \\
\text { severity }\end{array}$ & $\begin{array}{l}\text { Alcohol Use Disorders } \\
\text { Identification Test (AUDIT) (17) }\end{array}$ & Any score $\geq 20$ \\
$\begin{array}{l}\text { Psychiatric } \\
\text { symptoms }\end{array}$ & $\begin{array}{l}\text { Colorado Symptom Index (CSI) } \\
(18)\end{array}$ & $\begin{array}{l}\text { Experiencing suicidal or homicidal ideation } \\
\text { every day, or having visual or auditory } \\
\text { hallucinations more than once a month }\end{array}$ \\
\hline
\end{tabular}




\subsubsection{Recruitment}

In partnership with four shelter organizations in Metro Vancouver, our trained interviewers visited 22 homeless shelters to conduct the screening survey. The screening survey was described as a one-time study about the well-being of shelter guests, and there was no mention of the cash transfer. This cover story was used to prevent the news of the cash transfers from spreading and to ensure honest responses to the survey questions about substance use, alcohol use, and mental health. A total of 732 participants completed the screening survey and received a $\$ 20$ honorarium. Of those screened, 229 participants passed all six criteria (31\%) and were invited to complete another survey (i.e., baseline) at a time and location convenient to the participants. Eighty-five participants were excluded before the baseline survey, primarily due to being unreachable through all means of contact provided to the research team. At the baseline survey, participants were told that the study aimed to improve the social services provided to individuals experiencing homelessness, and would provide financial and non-financial supports to participants randomly assigned to different conditions. There was no detailed description of the amount of cash transfer or the non-cash supports. Only after completing the baseline survey, participants were given full details about the supports they would receive. Participant consent was obtained at each point that new information was provided to participants. Of the 144 participants who completed the baseline, 115 were successfully enrolled in the study, comprising our final study sample. Causes of participant attrition at each stage of the study are shown in Figure S2.

\subsubsection{Non-cash Interventions}

Workshop. The workshop was an in-person session where the interviewer guided the participants to complete a series of activities. The first workshop was mandatory and took place soon after the baseline survey (Median $=14$ days). Follow-up workshops were optional and occurred every three months after the cash transfer for a year. The goal of the workshop was to help participants brainstorm strategies to regain stability in their lives. The activities were designed based on past interventions in behavioral science that had demonstrated positive impacts on individuals (29). These activities included (1) self-affirmation where participants recalled a past successful personal experience and described the personal values most important to them; (2) demystifying success where participants discussed a successful person and the strategies the person used and they could adopt; (3) goal-setting where participants wrote down a clear and specific goal to achieve in the next year; (4) plan-making where participants identified steps to goal achievement and brainstormed potential obstacles and solutions; and (5) mental accounting which was only for the cash participants where they were encouraged to mentally set up a growth account for personal development and a flexible account for other expenses from the cash transfer. Participants in the cash group were required to complete a workshop after the baseline survey before they received the cash transfer. For the optional follow-up workshops, participants in the cash+workshop+coaching condition completed $77 \%$ of the workshops, participants in the cash+workshop condition completed $62 \%$, and participants in the workshop+coaching condition completed $65 \%$.

Coaching. Coaching consisted of three 45-minute phone calls per month for six months with a certified coach trained in the Co-Active Coaching Model from the Coaches Training Institute. All coaches volunteered their time for the experiment. Built upon the fundamentals of curiosity, 
non-judgement and partnering, the purpose of coaching was to help participants achieve their goals. Rather than using a teacher-student based approach, coaches encouraged participants to learn from their own experiences to increase self-efficacy in developing life skills and strategies to achieve their own goals. The coaches also completed additional training to learn the unique challenges that people experiencing homelessness may have encountered. Although coaching was offered three times a month, it was not highly utilized. The overall number of coaching sessions attended was low in the cash+workshop+coaching condition $(M=4.04, S D=3.84)$ and the workshop+coaching condition $(M=4.05, S D=3.44)$.

\subsubsection{Additional Supports}

All participants in the experiment were offered additional supports described below to facilitate the cash transfer and follow-up. Checking Account. In order for the cash transfer to be exempt from impacting eligibility of existing social benefits, all cash participants receiving the cash transfer were required to open a free Access Chequing Account to receive the funds at Vancity, a local credit union in Vancouver. This type of account offers 40 monthly transactions free of charge in addition to starter cheques at no cost. To mitigate differences between groups, this account was offered to both cash and control participants. Replacement ID. To open a checking account, participants were required to present one piece of government-issued ID plus a written letter from our project team. To ensure the ID requirement did not prevent people from opening an account, Vancity funded the cost of replacing government-issued ID for all participants. Case workers from the shelter supported participants through the application of replacement ID.

Resource booklet. All participants were provided with a resource booklet listing local resources for individuals experiencing homelessness in Metro Vancouver. The booklet included resources for crisis and mental health, housing, harm reduction, replacement ID, digital literacy, employment, volunteering, and health. Used Smartphone. All participants who did not own a working cell phone were offered a used smartphone. The phones were pre-loaded with an app that can call or text for free using WIFI, allowing participants to stay in touch with the research team.

\subsubsection{Follow-up Data Collection}

Follow-up surveys were conducted at 1, 3, 6, 9, and 12 months after the cash transfer with an interviewer in semi-private spaces (e.g. library meeting rooms, cafes). Each survey typically lasted between 1-2 hours, and participants were compensated $\$ 30$ for their time. Because the follow-up surveys were scheduled against the date of the cash transfer-rather than the date of the baseline survey - the length of time between the baseline survey and the 1-month follow-up was 63 days on average ( $S D=46$ days). To mitigate differences in survey intervals between cash and control participants, each control participant was matched to the timeline of a cash participant. Specifically, the dates of the follow-up surveys for control participants were assigned only after a matched cash participant received their cash transfer. Control participants were only matched to a cash participant if they completed the baseline within two weeks of each other. If such a match was not possible, the control participant was matched to the average delay (e.g., 63 days). Over 12-months, $30 \%$ of participants in the cash group dropped out (e.g. withdrawal, loss of contact, death) of the study, compared to $32 \%$ in the control group. A CONSORT Flow Diagram of participant attrition over 12 months is Figure S2. For both groups, the primary cause of attrition was loss of contact (Figure S2). In most cases, participants had moved or no longer had the same contact information. Compared to control participants, a larger number of cash 
recipients dropped out after baseline. The difference is partly due to the fact that all participants in the cash group who received the cash transfer were included in the final sample, whereas control participants were only included in the final sample if they completed at least one followup survey. In addition to participant attrition, some data are missing due to participants missing individual surveys. The total number of surveys completed at each time point are shown in Table S3.

Table S3. Number of surveys completed at each time point.

\begin{tabular}{lllllll}
\hline Condition & B & 1 mo. & 3 mo. & 6 mo. & 9 mo. & 12 mo. \\
\hline Cash & 48 & 37 & 35 & 36 & 27 & 26 \\
Non-Cash & 65 & 62 & 51 & 42 & 33 & 34
\end{tabular}

Notes. Two baseline surveys in the cash group were lost due to technical issues with the tablets recording the surveys. 
New Leaf Project CONSORT Flow Diagram

NOTE

Group 1: Cash, workshop, and coaching Considered a Good Complete after receiving cash transfer.

(c) Cassidered a er receiving cash transfer. Group 3: Workshop and coaching.

completing workshop, coaching, and at least 1 follow-up interview.

Group 4: No supports. Considered a Good Complete after completing at least 1 follow-up interview.

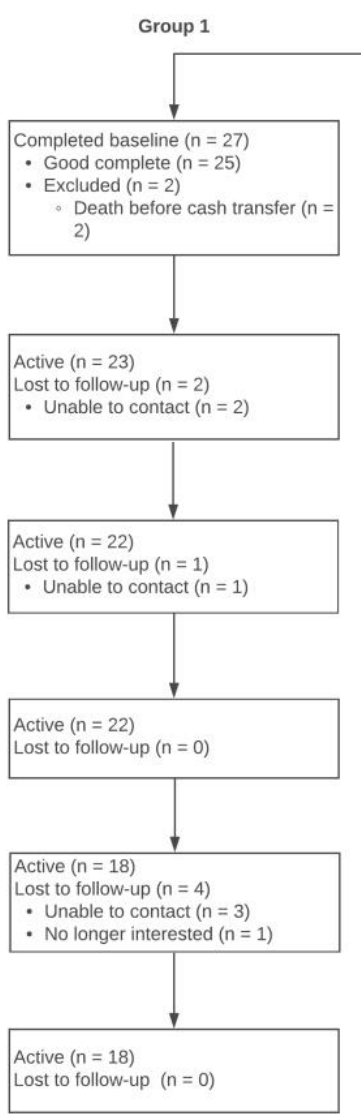

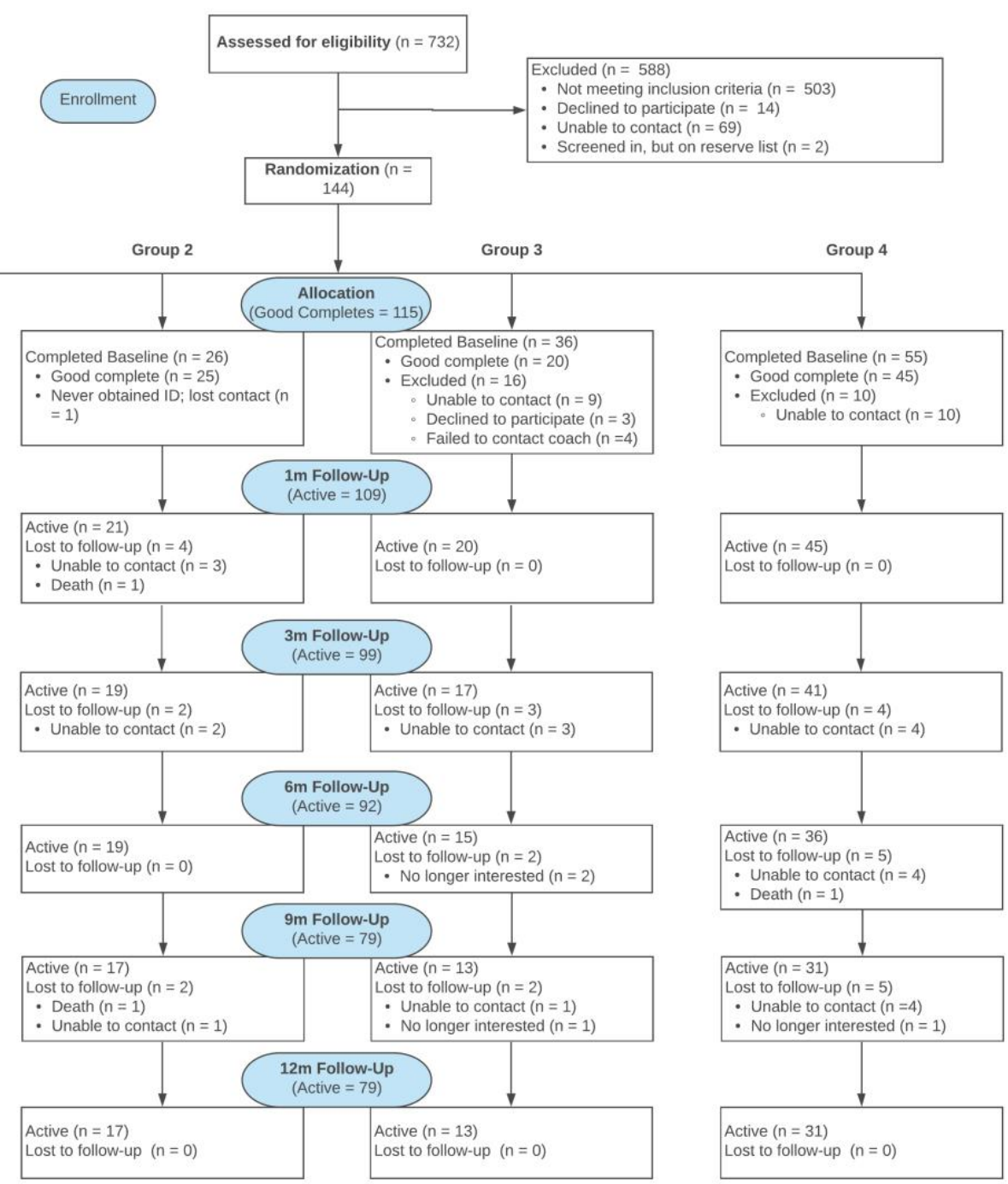

Figure S2. CONSORT Flow Diagram showing participant attrition over 12 months. 


\subsubsection{Dependent Measures}

Housing stability was measured using the Residential Timeline Follow Back (RTLFB) (30). This measure has been used in previous research with homeless populations and collects information about housing, including frequency of moves in a given time period and the type of residence. Assets and spending were measured using a consumption questionnaire adapted from a direct giving study in Kenya (12). This measure asks participants to report the amount of money spent on various items, including food, clothing, education, medical expenses etc. Participants were also asked to list any expenses over $\$ 50$ in order to track large expenditures. Employment, education, and income were measured using the Vocational Timeline Follow Back (VTLFB) (31). This measure has been used with homeless populations and has been designed to collect information about work, income, and education/vocational training. Cognitive functioning included executive function and fluid intelligence (32). Executive function was measured by 16 trials of a non-verbal spatial incompatibility task (33) where participants clicked a button on the same side of the screen when image A appears, but the opposite side of the screen when image B appears. Fluid intelligence was measured by 10 trials of Raven's Progressive Matrices (34) where participants viewed a matrix with a missing corner and had to find the correct piece that fit the pattern in the matrix. Subjective well-being contained multiple measures. Life Satisfaction was a 5-item measure used to assess global cognitive judgments of one's life satisfaction (35). The Scale of Positive and Negative Affect was a 12-item questionnaire that assesses positive and negative feelings (36). Quality of life was measured using the Quality of Life Index (37). Social connection was measured using the 11item Social Connectedness Scale (38), and two additional items assessed the availability of a confidant (39). Self-efficacy was measured using the General Self-Efficacy Scale (40). Sense of empowerment was measured using the Personal Empowerment Scale (41). Psychiatric Symptomatology was measured using the Colorado Symptom Index (18). Food security was measured using the Adult Food Security Survey Module (42). Substance use severity was measured by the DAST-10 (16) and alcohol use severity was measured by the AUDIT (17). Social Service Use measured health and social service use using the Health, Social, and Justice Service Use (HSJSU) Inventory that was developed by the At Home/Chez Soi project team for specific use with homeless populations (43). This instrument was used to examine changes in service use and to inform the cost-benefit analysis. We also measured health status using the SF12 v2 (44) which consisted of 12 questions on physical functioning and health. However due to licensing issues, we did not analyze this outcome.

\subsubsection{Debriefing}

Participants were debriefed after they completed the 12-month follow-up survey. Participants were provided with full details about the study design and research hypotheses, and were given the opportunity to withdraw their data from the study. Finally, participants were asked if they would like to receive a copy of a final community report about the project, and asked to provide their contact information if they would like to remain in touch for any additional opportunities.

\subsection{Results}

\subsubsection{Preregistered Analyses}


Confirmatory analyses were preregistered on the OSF (osf.io/e68ab). Since we had limited evidence to make predictions, we preregistered only a small set of analyses, which predicted better cognitive and subjective well-being outcomes for the cash group at one month after the cash transfer. We pre-registered three hypotheses:

H1. Participants who receive cash transfers will demonstrate better outcomes than those who do not receive cash transfers.

$\mathrm{H} 2$. Cash recipients who take part in personal coaching will demonstrate better outcomes than cash recipients who do not take part in coaching.

H3. Non-cash participants who take part in the workshop + coaching program will demonstrate better outcomes than those who do not undertake this program.

Based on the preregistration, for each of our three hypotheses, we assessed the following measures: fluid intelligence, executive functioning, satisfaction with life, positive affect, negative affect, subjective well-being, and self-efficacy. For executive function, we computed accuracy (the number of items answered correctly divided by the total number of items) and an efficiency score (the accuracy divided by the mean reaction time of correct trials). For fluid intelligence, we only computed accuracy since it wasn't a timed task. Participants were assigned to one of four treatment arms (2 cash groups and 2 non-cash groups):

1. Group 1: cash + workshop + coaching $(n=25)$

2. Group 2: cash + workshop, no coaching $(n=25)$

3. Group 3: no cash, workshop + coaching $(n=19)$

4. Group 4: no cash, no workshop, no coaching $(n=46)$

The workshop contained a one-hour session on self-affirmation, goal setting, and plan making with the interviewer every three months, and coaching contained three 45-minute phone calls per month with a life coach. We did not find significant differences between conditions 1 and 2, or between conditions 3 and 4, thus - in line with our pre-registration - we combined the first two conditions into the cash group $(n=50)$ and the last two conditions into the control group $(n=$ $65)$.

To test Hypothesis 1, we compared the combined cash groups to each control group at the 1month follow-up. For each outcome measure, we conducted a 2 (time: Baseline vs. 1-month) X 3 (condition: Group 1+2 vs. Group 3 vs. Group 4) mixed-effects ANOVA to examine if the groups differ in their change from baseline to the 1-month follow-up. These results are presented in Table S4. None of the interactions were significant, so we did not follow up with any simple effects analyses.

Table S4. Preregistered analysis 1. Omnibus ANOVA testing the interaction between conditions and time point.

\begin{tabular}{lcclcc}
\hline Outcome & sumsq & meansq & df & F & p \\
\hline Fluid Intelligence Accuracy & 0.108 & 0.054 & $2,69.35$ & 2.440 & 0.094
\end{tabular}




\begin{tabular}{lccccc} 
Executive Function Accuracy & 0.087 & 0.044 & $2,51.42$ & 1.470 & 0.239 \\
Executive Function Efficiency & 1.020 & 0.509 & $2,73.09$ & 0.233 & 0.793 \\
Subjective Wellbeing & 1.000 & 0.500 & $2,95.71$ & 2.300 & 0.106 \\
Satisfaction with Life & 0.747 & 0.374 & $2,97.38$ & 0.523 & 0.595 \\
Positive Affect & 1.500 & 0.748 & $2,97.3$ & 2.590 & 0.081 \\
Negative Affect & 0.714 & 0.357 & $2,96.65$ & 1.130 & 0.327 \\
Self-Efficacy & 2.530 & 1.260 & $2,91.28$ & 0.205 & 0.815 \\
\hline
\end{tabular}

To test Hypothesis 2, we compared Groups 1 and 2 to examine the impact of coaching at 1month follow-up. For each primary outcome measure, we conducted a 2 (time: Baseline vs. 1month) X 2 (condition: Groups 1 vs. 2) mixed-effects ANOVA to examine if the two groups differ in their change from baseline to the 1-month follow-up. These results are presented in Table S5. None of the interactions were significant, so we did not follow up with any simple effects analyses.

Table S5. Preregistered analysis 2. Omnibus ANOVA testing the interaction between conditions and time point.

\begin{tabular}{llllll}
\hline Outcome & sumsq & meansq & df & F & p \\
\hline Fluid Intelligence Accuracy & 0.000 & 0.000 & $1,28.83$ & 0.001 & 0.978 \\
Executive Function Accuracy & 0.008 & 0.008 & $1,24.2$ & 0.179 & 0.676 \\
Executive Function Efficiency & 0.002 & 0.002 & 1,47 & 0.003 & 0.958 \\
Subjective Wellbeing & 0.785 & 0.785 & $1,34.56$ & 3.270 & 0.079 \\
Satisfaction with Life & 1.720 & 1.720 & $1,37.54$ & 2.020 & 0.164 \\
Positive Affect & 1.120 & 1.120 & $1,35.95$ & 4.140 & 0.049 \\
Negative Affect & 0.314 & 0.314 & $1,34.28$ & 1.090 & 0.305 \\
Self-Efficacy & 1.240 & 1.240 & $1,32.55$ & 0.246 & 0.623 \\
\hline
\end{tabular}

To test Hypothesis 3, we compared Groups 3 and 4 to examine the impact of workshop and coaching at 1-month follow-up. For each primary outcome measure, we conducted a 2 (time: 
Baseline vs. 1-month) X 2 (condition: Groups 3 vs. 4) mixed-effects ANOVA to examine if the two groups differed in their change from baseline to the 1-month follow-up. These results are presented in Table S6. None of the interactions were significant, so we did not follow up with any simple effects analyses.

Table S6. Preregistered analysis 3. Omnibus ANOVA testing the interaction between conditions and time point.

\begin{tabular}{llllll}
\hline Outcome & sumsq & meansq & df & F & p \\
\hline Fluid Intelligence Accuracy & 0.079 & 0.079 & $1,40.29$ & 3.480 & 0.069 \\
Executive Function Accuracy & 0.035 & 0.035 & $1,28.49$ & 1.560 & 0.222 \\
Executive Function Efficiency & 0.727 & 0.727 & $1,40.96$ & 0.212 & 0.647 \\
Subjective Wellbeing & 0.014 & 0.014 & $1,60.21$ & 0.071 & 0.791 \\
Satisfaction with Life & 0.012 & 0.012 & $1,60.2$ & 0.020 & 0.889 \\
Positive Affect & 0.005 & 0.005 & $1,60.26$ & 0.018 & 0.893 \\
Negative Affect & 0.057 & 0.057 & $1,61.12$ & 0.170 & 0.682 \\
Self-Efficacy & 0.157 & 0.157 & $1,57.98$ & 0.023 & 0.879 \\
& & & & & \\
\hline
\end{tabular}




\subsubsection{Exploratory Analyses}

Since there was no significant difference between groups 1 and 2, and between groups 3 and 4, we combined the two cash groups into one cash group, and the two non-cash groups into one control group. We conducted exploratory analyses of all outcomes between the two groups at all follow-up time points.

Analytic Approach. Because participants provided data at multiple time points and because participants were clustered within shelters, we employed multilevel modeling to account for nonindependence. In these data, time points (level-1) are nested within participants (level-2), who are nested within shelters (level-3). For each model, we used restricted maximum likelihood estimation, and we included random intercepts that varied across individuals. In our primary analyses testing the overall effects across the 12-month follow-up period, time point was coded 0 $=$ baseline and $1=$ follow-up. In our secondary analyses testing the effects over time, time point was dummy coded to identify each time point (i.e., baseline, 1-month, 3-month, 6-month, 9month, and 12-month), treating baseline as the reference category (see Equation 1). To control the false discovery rate of our primary analyses, we used the Benjamini-Hochberg Procedure to adjust the p-values of the overall tests $\left(n_{-}\right.$tests $\left.=54\right)(19)$. To promote the discovery of potential impacts over time, the tests at individual time points were left unadjusted. These tests should be treated as very tentative and exploratory. Additional details of the analyses are provided in the main text.

\section{Equation S1.}

$$
\begin{gathered}
\text { outcome }_{i j}=\gamma_{00}+\gamma_{01} \text { condition }_{j}+u_{0 j}+\left(\gamma_{10}+\gamma_{11} \text { condition }_{j}\right) \text { time }_{i j}+\left(\gamma_{20}+\gamma_{21} \text { condition }_{j}\right) \text { time }_{i j}+ \\
\left(\gamma_{30}+\gamma_{31} \text { condition }_{j}\right) \text { time }_{i j}+\left(\gamma_{40}+\gamma_{41} \text { condition }_{j}\right) \text { time }_{i j}+\left(\gamma_{50}+\gamma_{51} \text { condition }_{j}\right) \text { time } 2_{i j}+e_{i j}
\end{gathered}
$$

For each outcome, we were concerned primarily with the interaction between condition and time point. Taking the one-month time point as an example, a significant interaction would suggest that the change from baseline to one month in the cash group was different from the change from baseline to one month in the non-cash group. Thus, our analytic approach tested for differences in changes between the groups at each time point relative to baseline.

\section{Additional Standardized Treatment Effects}

Additional standardized treatment effects across time are shown in Table S7. Cash recipients spent relatively more days in temporary housing. Cash participants also reported decreased quality of leisure time, which is one of the only negative findings observed in the study. Among participants who receive income assistance, participants who received the cash transfer received relatively more assistance than non-cash participants (there are many possible reasons this could have occurred: the cash may have provided the means to apply for additional assistance, obtaining and ID and bank account may have made it easier to receive additional funds, etc). Among participants who rented housing, participants who received cash spent relatively more each month on rent than non-cash participants.

Table S7. Additional standardized treatment effects. Only the overall effects are corrected for multiple comparisons. 


\begin{tabular}{l}
\hline Domain \\
\hline Housing Stability
\end{tabular}

$\begin{array}{lllllll}\text { Days in Temporary } & 0.56^{*} & 0.3 & 0.63^{*} & 0.5 & 0.91^{* *} & 0.56^{*} \\ \text { Housing } & (0.28) & (0.28) & (0.29) & (0.32) & (0.32) & (0.21)\end{array}$

Income

$\begin{array}{lllllll}\text { Income Assistance } & 0.34 & 0.79 * * & 0.58^{*} & 0.41 & 0.86^{*} & 0.6^{*} \\ \text { (Recipients Only) } & (0.23) & (0.25) & (0.28) & (0.33) & (0.33) & (0.2)\end{array}$

Spending

$\begin{array}{lllllll}\text { Childcare } & 0.43 & -0.17 & 0.54 & 0.24 & 1 \dagger & 0.36 \\ & (0.47) & (0.48) & (0.52) & (0.53) & (0.5) & (0.36) \\ \text { Clothes for Kids } & 0.1 & -0.08 & -0.26 & -0.36 & -0.34 & -0.18 \\ & (0.41) & (0.42) & (0.48) & (0.46) & (0.45) & (0.31) \\ \text { Food for Kids } & 0.36 & 0.28 & -0.01 & 0.08 & 0.59 & 0.27 \\ & (0.39) & (0.38) & (0.43) & (0.43) & (0.41) & (0.29) \\ \text { Rent (Renters Only) } & 0.01 & 0.65^{*} & 0.66^{*} & 0.86^{* *} & 0.88^{*} & 0.66 \dagger \\ & (0.37) & (0.32) & (0.32) & (0.33) & (0.34) & (0.28)\end{array}$

Employment

$\begin{array}{lllllll}\begin{array}{l}\text { Hourly Pay } \\ \text { (Workers) }\end{array} & 0.6 \dagger & 0.56 & 0.63 \dagger & 0.34 & 0.44 & 0.49 \\ & (0.34) & (0.34) & (0.35) & (0.37) & (0.4) & (0.28) \\ \begin{array}{l}\text { Weekly Job Hours } \\ \text { (Workers) }\end{array} & 0.58 & -0.02 & 0.72 * & 0.62 & 0.87 * & 0.49 \\ & (0.35) & (0.36) & (0.36) & (0.39) & (0.41) & (0.29)\end{array}$

Education

$\begin{array}{lllllll}\text { Weekly Course Hours } & & 0.13 & 0.34 & 1.3 \dagger & 2.87 * & 0.77 \\ \text { (Students) } & - & (0.7) & (0.86) & (0.76) & (1.06) & (0.64)\end{array}$

Cognitive

Functioning

$\begin{array}{lllllll}\text { Executive Function } & -0.2 & 0.06 & -0.64 \dagger & -0.77^{*} & -1.25^{* *} & -0.38 \\ \text { Efficiency } & (0.33) & (0.33) & (0.35) & (0.38) & (0.4) & (0.26)\end{array}$

Subjective Wellbeing

\begin{tabular}{lllllll}
\multirow{2}{*}{ Subjective Wellbeing } & $0.34^{*}$ & 0.11 & -0.06 & 0.03 & 0.3 & 0.17 \\
& $(0.17)$ & $(0.17)$ & $(0.18)$ & $(0.19)$ & $(0.19)$ & $(0.13)$
\end{tabular}

Quality of Life 


\begin{tabular}{|c|c|c|c|c|c|c|c|}
\hline Domain & Outcome & $1 \mathrm{~m}$ & $3 m$ & $6 \mathrm{~m}$ & $9 m$ & $12 \mathrm{~m}$ & Overall \\
\hline & $\begin{array}{l}\text { Quality of Life - } \\
\text { Family }\end{array}$ & - & $\begin{array}{l}0.01 \\
(0.19)\end{array}$ & $\begin{array}{l}-0.23 \\
(0.2)\end{array}$ & $\begin{array}{l}-0.16 \\
(0.22)\end{array}$ & $\begin{array}{l}-0.08 \\
(0.22)\end{array}$ & $\begin{array}{l}-0.1 \\
(0.15)\end{array}$ \\
\hline & $\begin{array}{l}\text { Quality of Life - } \\
\text { Finances }\end{array}$ & - & $\begin{array}{l}0.38^{*} \\
(0.19)\end{array}$ & $\begin{array}{l}0.15 \\
(0.19)\end{array}$ & $\begin{array}{l}-0.32 \\
(0.21)\end{array}$ & $\begin{array}{l}0.1 \\
(0.22)\end{array}$ & $\begin{array}{l}0.12 \\
(0.15)\end{array}$ \\
\hline & $\begin{array}{l}\text { Quality of Life - } \\
\text { Leisure }\end{array}$ & - & $\begin{array}{l}-0.09 \\
(0.2)\end{array}$ & $\begin{array}{l}-0.5 * \\
(0.2)\end{array}$ & $\begin{array}{l}-0.42 \dagger \\
(0.23)\end{array}$ & $\begin{array}{l}-0.4 \dagger \\
(0.23)\end{array}$ & $\begin{array}{l}-0.32 \\
(0.16)\end{array}$ \\
\hline & $\begin{array}{l}\text { Quality of Life - } \\
\text { Living }\end{array}$ & - & $\begin{array}{l}0.18 \\
(0.25)\end{array}$ & $\begin{array}{l}-0.23 \\
(0.25)\end{array}$ & $\begin{array}{l}-0.11 \\
(0.28)\end{array}$ & $\begin{array}{l}-0.38 \\
(0.28)\end{array}$ & $\begin{array}{l}-0.1 \\
(0.19)\end{array}$ \\
\hline & $\begin{array}{l}\text { Quality of Life - } \\
\text { Safety }\end{array}$ & - & $\begin{array}{l}0.16 \\
(0.22)\end{array}$ & $\begin{array}{l}0.03 \\
(0.23)\end{array}$ & $\begin{array}{l}-0.12 \\
(0.25)\end{array}$ & $\begin{array}{l}-0.06 \\
(0.25)\end{array}$ & $\begin{array}{l}0.03 \\
(0.18)\end{array}$ \\
\hline & $\begin{array}{l}\text { Quality of Life - } \\
\text { Social }\end{array}$ & - & $\begin{array}{l}-0.25 \\
(0.24)\end{array}$ & $\begin{array}{l}-0.03 \\
(0.25)\end{array}$ & $\begin{array}{l}-0.49 \dagger \\
(0.27)\end{array}$ & $\begin{array}{l}-0.52 \dagger \\
(0.28)\end{array}$ & $\begin{array}{l}-0.28 \\
(0.19)\end{array}$ \\
\hline \multicolumn{8}{|c|}{ Service Use } \\
\hline & $\begin{array}{l}\text { Cost of Police } \\
\text { Services }\end{array}$ & - & $\begin{array}{l}-0.17 \\
(0.24)\end{array}$ & $\begin{array}{l}0.16 \\
(0.25)\end{array}$ & $\begin{array}{l}-0.04 \\
(0.27)\end{array}$ & $\begin{array}{l}-0.14 \\
(0.27)\end{array}$ & $\begin{array}{l}-0.05 \\
(0.19)\end{array}$ \\
\hline & $\begin{array}{l}\text { Cost of Health and } \\
\text { Social Services }\end{array}$ & - & $\begin{array}{l}-0.08 \\
(0.26)\end{array}$ & $\begin{array}{l}-0.05 \\
(0.26)\end{array}$ & $\begin{array}{l}0.04 \\
(0.29)\end{array}$ & $\begin{array}{l}-0.1 \\
(0.29)\end{array}$ & $\begin{array}{l}-0.07 \\
(0.2)\end{array}$ \\
\hline
\end{tabular}

Notes. Due to limited data points, the following outcomes were unable to be analyzed: days in institutional housing, cost of justice services, cost of police services. 

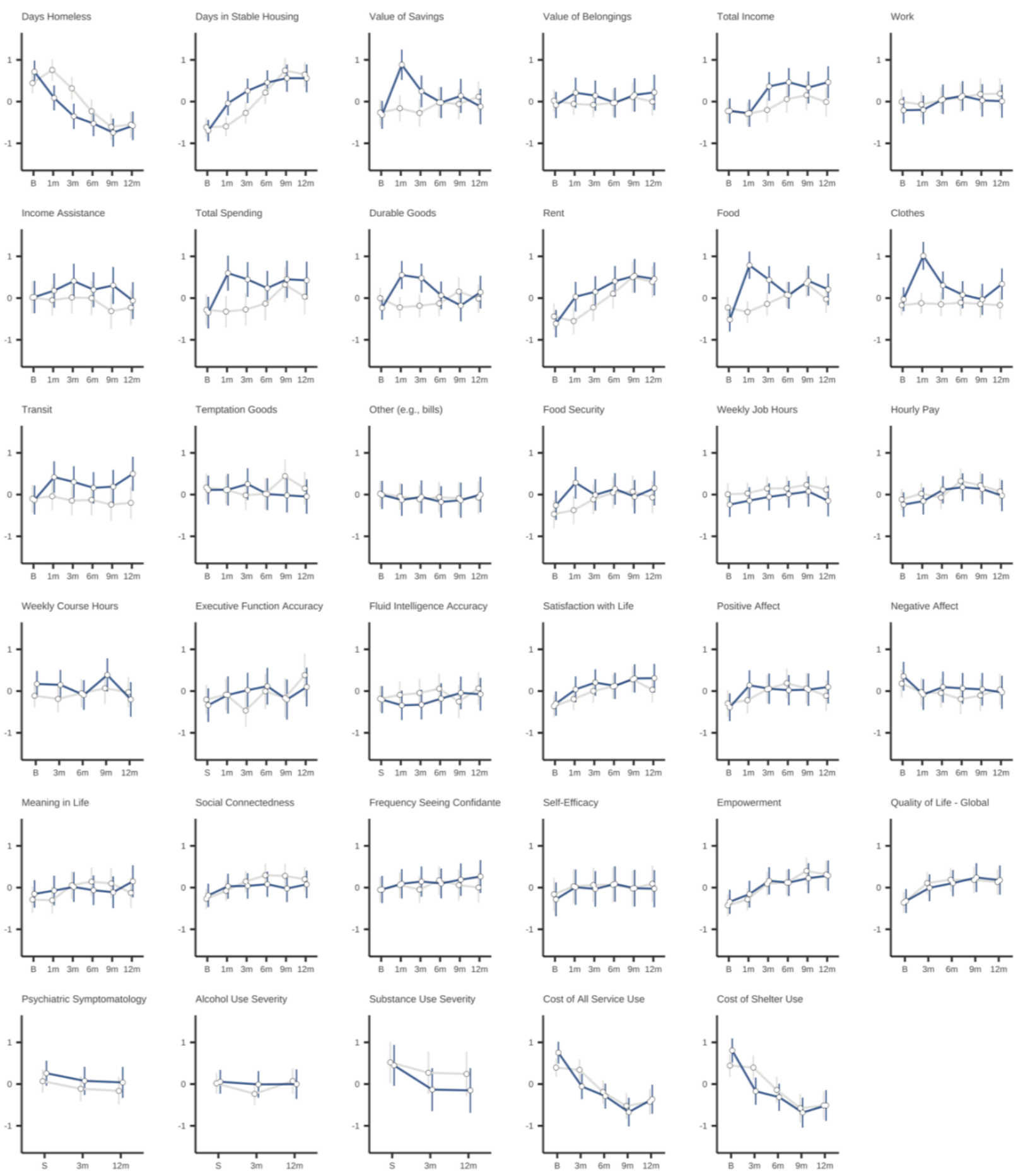

$$
+{ }^{\text {control }}+{ }^{\text {cash }}
$$

Figure S3. Overview of primary outcomes (standardized) over 12 months. The blue line represents the averages of the cash group, and the gray line represents the averages of the control group. Error bars represent $95 \%$ confidence intervals. 


\subsubsection{Sensitivity Analyses}

To determine the robustness of the effects we observed, we conducted sensitivity analyses to examine the effects derived from various analytic approaches. The different analyses are described below, and comparison of the overall standardized effects across analytic approaches is presented in Table S8. To quantify the extent to which each analytic approach differed from our primary analysis, the mean absolute difference across all measures is included in the final row of the table.

Overall, the results obtained in our primary analysis were robust across analytic approaches. The mean absolute differences between the primary analysis and the other five approaches ranged between .05 and .12 , suggesting that the estimates we obtained are relatively stable.

\section{Covariates}

To assess whether differences in baseline characteristics might account for the observed effects, the following covariates were added to the model: gender, age, disability recipient, substance use dependence disorder clinical diagnosis, substance use dependence disorder self-diagnosis, psychiatric symptomatology, substance use severity, alcohol use severity, number of children, recipient of income assistance, income, total duration of homeless during lifetime, duration of most recent experience of homelessness, self-identified mental health disorder, cash transfer delay, coaching, and workshop.

\section{Only participants who completed full 6 months}

Because a number of participants dropped out after 6 months, it is possible that self-selection may have skewed the results at later time points. By restricting the data to 6 months, this data should reduce the potential bias for self-selection from the later time points.

\section{Outliers included}

Unlike our primary dataset, this dataset includes all outliers.

\section{Imputed with last observation carried forward}

In this dataset, missing data have been imputed by carrying forward the last response recorded from previous timepoints. For example, if a participant reported total assets of $\$ 0$ at baseline, but did not complete any future surveys, all subsequent surveys would be filled in with $\$ 0$. The purpose is to address the possibility that participants are most likely to drop out when they are in unstable circumstances. By carrying the participants' last known status forward, this approach assumes participants who dropped out experienced no improvements. However, it should be noted that this method also decreases estimates of within participant error, so significance tests under this approach will be liberally biased.

\section{Delayed cash participants removed}

Nine participants who received the cash transfer more than 100 days after the baseline survey were removed $(M=53, S D=66$, Median $=23)$. These gaps were due primarily to delays obtaining replacement ID. This analysis was done in order to ensure that these participants didn't simply have more time to achieve stability. 
Table S8. Comparison of overall standardized effects across analytic approaches.

\begin{tabular}{|c|c|c|c|c|c|c|c|}
\hline Domain & Outcome & Primary & Covariates & Full 6m & w/ Outliers & Imputed & No Delay \\
\hline \multicolumn{8}{|c|}{ Housing Stability } \\
\hline & Days Homeless & $\begin{array}{l}-0.75^{* * * *} \\
(0.18)\end{array}$ & $\begin{array}{l}-0.67 * * \\
(0.22)\end{array}$ & $\begin{array}{l}-0.74^{* *} \\
(0.23)\end{array}$ & $\begin{array}{l}-0.74 * * * \\
(0.17)\end{array}$ & $\begin{array}{l}-0.61 * * * \\
(0.16)\end{array}$ & $\begin{array}{l}-0.76^{* * * *} \\
(0.2)\end{array}$ \\
\hline & Days in Stable Housing & $\begin{array}{l}0.42 * \\
(0.18)\end{array}$ & $\begin{array}{l}0.26 \\
(0.22)\end{array}$ & $\begin{array}{l}0.5^{*} \\
(0.23)\end{array}$ & $\begin{array}{l}0.4^{*} \\
(0.17)\end{array}$ & $\begin{array}{l}0.33 * \\
(0.16)\end{array}$ & $\begin{array}{l}0.46^{*} \\
(0.19)\end{array}$ \\
\hline \multicolumn{8}{|l|}{ Assets } \\
\hline & Value of Savings & $\begin{array}{l}0.45^{*} \\
(0.17)\end{array}$ & $\begin{array}{l}0.41 \\
(0.23)\end{array}$ & $\begin{array}{l}0.69 * * \\
(0.21)\end{array}$ & $\begin{array}{l}0.17 \\
(0.11)\end{array}$ & $\begin{array}{l}0.4 * * \\
(0.14)\end{array}$ & $\begin{array}{l}0.39 * \\
(0.19)\end{array}$ \\
\hline & Value of Belongings & $\begin{array}{l}0.26 \\
(0.19)\end{array}$ & $\begin{array}{l}-0.1 \\
(0.22)\end{array}$ & $\begin{array}{l}0.34 \\
(0.25)\end{array}$ & $\begin{array}{l}0.14 \\
(0.17)\end{array}$ & $\begin{array}{l}0.08 \\
(0.13)\end{array}$ & $\begin{array}{l}0.25 \\
(0.2)\end{array}$ \\
\hline \multicolumn{8}{|l|}{ Income } \\
\hline & Total Income & $\begin{array}{l}0.34 \\
(0.19)\end{array}$ & $\begin{array}{l}0.45^{*} \\
(0.22)\end{array}$ & $\begin{array}{l}0.48 * \\
(0.24)\end{array}$ & $\begin{array}{l}0.28 \\
(0.17)\end{array}$ & $\begin{array}{l}0.32 * \\
(0.15)\end{array}$ & $\begin{array}{l}0.32 \\
(0.2)\end{array}$ \\
\hline & Work & $\begin{array}{l}0.15 \\
(0.16)\end{array}$ & $\begin{array}{l}0.33 \\
(0.19)\end{array}$ & $\begin{array}{l}0.19 \\
(0.19)\end{array}$ & $\begin{array}{l}0.16 \\
(0.15)\end{array}$ & $\begin{array}{l}0.23 \\
(0.13)\end{array}$ & $\begin{array}{l}0.08 \\
(0.17)\end{array}$ \\
\hline & Income Assistance & $\begin{array}{l}0.29 \\
(0.16)\end{array}$ & $\begin{array}{l}0.4^{*} \\
(0.19)\end{array}$ & $\begin{array}{l}0.39 \\
(0.22)\end{array}$ & $\begin{array}{l}0.36 * \\
(0.16)\end{array}$ & $\begin{array}{l}0.23 \\
(0.13)\end{array}$ & $\begin{array}{l}0.34 \\
(0.18)\end{array}$ \\
\hline \multicolumn{8}{|c|}{ Spending } \\
\hline & Total Spending & $\begin{array}{l}0.63 * * * \\
(0.17)\end{array}$ & $\begin{array}{l}0.77^{* * * *} \\
(0.21)\end{array}$ & $\begin{array}{l}0.75^{*} * \\
(0.23)\end{array}$ & $\begin{array}{l}0.44 * * * \\
(0.11)\end{array}$ & $\begin{array}{l}0.48 * * \\
(0.14)\end{array}$ & $\begin{array}{l}0.75^{* * * *} \\
(0.18)\end{array}$ \\
\hline & Durable Goods & $\begin{array}{l}0.57 * * \\
(0.21)\end{array}$ & $\begin{array}{l}0.66^{*} \\
(0.26)\end{array}$ & $\begin{array}{l}0.84 * * \\
(0.29)\end{array}$ & $\begin{array}{l}0.5 * * \\
(0.19)\end{array}$ & $\begin{array}{l}0.57 * * \\
(0.19)\end{array}$ & $\begin{array}{l}0.54 * \\
(0.23)\end{array}$ \\
\hline & Rent & $\begin{array}{l}0.54 * * \\
(0.19)\end{array}$ & $\begin{array}{l}0.34 \\
(0.22)\end{array}$ & $\begin{array}{l}0.47 \\
(0.25)\end{array}$ & $\begin{array}{l}0.54 * * \\
(0.18)\end{array}$ & $\begin{array}{l}0.4^{*} \\
(0.16)\end{array}$ & $\begin{array}{l}0.57^{* *} \\
(0.2)\end{array}$ \\
\hline & Food & $\begin{array}{l}0.76 * * * \\
(0.18)\end{array}$ & $\begin{array}{l}0.87 * * * \\
(0.22)\end{array}$ & $\begin{array}{l}0.9 * * * \\
(0.22)\end{array}$ & $\begin{array}{l}0.56 * * * \\
(0.14)\end{array}$ & $\begin{array}{l}0.59 * * * \\
(0.14)\end{array}$ & $\begin{array}{l}0.84 * * * \\
(0.19)\end{array}$ \\
\hline & Clothes & $\begin{array}{l}0.34 \\
(0.2)\end{array}$ & $\begin{array}{l}0.55^{*} \\
(0.25)\end{array}$ & $\begin{array}{l}0.26 \\
(0.27)\end{array}$ & $\begin{array}{l}0.14 \\
(0.1)\end{array}$ & $\begin{array}{l}0.29 \\
(0.15)\end{array}$ & $\begin{array}{l}0.24 \\
(0.2)\end{array}$ \\
\hline & Transit & $\begin{array}{l}0.47 * * \\
(0.17)\end{array}$ & $\begin{array}{l}0.71 * * \\
(0.22)\end{array}$ & $\begin{array}{l}0.34 \\
(0.23)\end{array}$ & $\begin{array}{l}0.31 * \\
(0.15)\end{array}$ & $\begin{array}{l}0.36 * \\
(0.15)\end{array}$ & $\begin{array}{l}0.43 * \\
(0.18)\end{array}$ \\
\hline & Temptation Goods & $\begin{array}{l}0.03 \\
(0.17)\end{array}$ & $\begin{array}{l}0.18 \\
(0.22)\end{array}$ & $\begin{array}{l}0.12 \\
(0.2)\end{array}$ & $\begin{array}{l}-0.09 \\
(0.14)\end{array}$ & $\begin{array}{l}-0.02 \\
(0.13)\end{array}$ & $\begin{array}{l}0.03 \\
(0.18)\end{array}$ \\
\hline & Other (e.g., bills) & $\begin{array}{l}0 \\
(0.2)\end{array}$ & $\begin{array}{l}0.04 \\
(0.24)\end{array}$ & $\begin{array}{l}-0.19 \\
(0.28)\end{array}$ & $\begin{array}{l}0.14 \\
(0.2)\end{array}$ & $\begin{array}{l}-0.07 \\
(0.15)\end{array}$ & $\begin{array}{l}-0.01 \\
(0.21)\end{array}$ \\
\hline \multicolumn{8}{|c|}{ Food Security } \\
\hline & Food Security & $\begin{array}{l}0.03 \\
(0.17)\end{array}$ & $\begin{array}{l}-0.09 \\
(0.21)\end{array}$ & $\begin{array}{l}0.06 \\
(0.24)\end{array}$ & $\begin{array}{l}0.05 \\
(0.17)\end{array}$ & $\begin{array}{l}0.06 \\
(0.14)\end{array}$ & $\begin{array}{l}-0.06 \\
(0.18)\end{array}$ \\
\hline \multicolumn{8}{|c|}{ Employment } \\
\hline & Weekly Job Hours & $\begin{array}{l}0.07 \\
(0.16)\end{array}$ & $\begin{array}{l}0.06 \\
(0.18)\end{array}$ & $\begin{array}{l}0.02 \\
(0.2)\end{array}$ & $\begin{array}{l}0.06 \\
(0.15)\end{array}$ & $\begin{array}{l}0.1 \\
(0.13)\end{array}$ & $\begin{array}{l}0.02 \\
(0.16)\end{array}$ \\
\hline & Hourly Pay & $\begin{array}{l}0.08 \\
(0.18)\end{array}$ & $\begin{array}{l}0.13 \\
(0.22)\end{array}$ & $\begin{array}{l}0.14 \\
(0.24)\end{array}$ & $\begin{array}{l}0.05 \\
(0.16)\end{array}$ & $\begin{array}{l}0.07 \\
(0.14)\end{array}$ & $\begin{array}{l}-0.01 \\
(0.19)\end{array}$ \\
\hline \multicolumn{8}{|c|}{ Education } \\
\hline & Weekly Course Hours & $\begin{array}{l}-0.16 \\
(0.23)\end{array}$ & $\begin{array}{l}-0.08 \\
(0.26)\end{array}$ & $\begin{array}{l}-0.16 \\
(0.32)\end{array}$ & $\begin{array}{l}-0.28 \\
(0.2)\end{array}$ & $\begin{array}{l}-0.12 \\
(0.18)\end{array}$ & $\begin{array}{l}-0.23 \\
(0.24)\end{array}$ \\
\hline \multicolumn{8}{|c|}{ Cognitive Functioning } \\
\hline & Executive Function Accuracy & $\begin{array}{l}0.27 \\
(0.22)\end{array}$ & $\begin{array}{l}0.3 \\
(0.27)\end{array}$ & $\begin{array}{l}0.13 \\
(0.31)\end{array}$ & $\begin{array}{l}0.18 \\
(0.19)\end{array}$ & $\begin{array}{l}0.12 \\
(0.13)\end{array}$ & $\begin{array}{l}0.42 \\
(0.24)\end{array}$ \\
\hline & Fluid Intelligence Accuracy & $\begin{array}{l}-0.15 \\
(0.13)\end{array}$ & $\begin{array}{l}-0.03 \\
(0.16)\end{array}$ & $\begin{array}{l}-0.22 \\
(0.17)\end{array}$ & $\begin{array}{l}-0.13 \\
(0.12)\end{array}$ & $\begin{array}{l}-0.1 \\
(0.08)\end{array}$ & $\begin{array}{l}-0.09 \\
(0.14)\end{array}$ \\
\hline \multicolumn{8}{|c|}{ Subjective Well-being } \\
\hline & Satisfaction with Life & $\begin{array}{l}0.12 \\
(0.13)\end{array}$ & $\begin{array}{l}0.15 \\
(0.16)\end{array}$ & $\begin{array}{l}0.15 \\
(0.17)\end{array}$ & $\begin{array}{l}0.08 \\
(0.13)\end{array}$ & $\begin{array}{l}0.07 \\
(0.11)\end{array}$ & $\begin{array}{l}0.12 \\
(0.14)\end{array}$ \\
\hline
\end{tabular}




\begin{tabular}{|c|c|c|c|c|c|c|c|}
\hline Domain & Outcome & Primary & Covariates & Full 6m & w/ Outliers & Imputed & No Delay \\
\hline & Positive Affect & $\begin{array}{l}0.2 \\
(0.16)\end{array}$ & $\begin{array}{l}0.25 \\
(0.19)\end{array}$ & $\begin{array}{l}0.15 \\
(0.19)\end{array}$ & $\begin{array}{l}0.18 \\
(0.15)\end{array}$ & $\begin{array}{l}0.12 \\
(0.13)\end{array}$ & $\begin{array}{l}0.1 \\
(0.16)\end{array}$ \\
\hline & Negative Affect & $\begin{array}{l}-0.1 \\
(0.14)\end{array}$ & $\begin{array}{l}-0.2 \\
(0.17)\end{array}$ & $\begin{array}{l}-0.26 \\
(0.18)\end{array}$ & $\begin{array}{l}-0.04 \\
(0.14)\end{array}$ & $\begin{array}{l}-0.05 \\
(0.12)\end{array}$ & $\begin{array}{l}-0.11 \\
(0.15)\end{array}$ \\
\hline & Meaning in Life & $\begin{array}{l}-0.1 \\
(0.15)\end{array}$ & $\begin{array}{l}-0.01 \\
(0.18)\end{array}$ & $\begin{array}{l}-0.22 \\
(0.2)\end{array}$ & $\begin{array}{l}-0.08 \\
(0.14)\end{array}$ & $\begin{array}{l}-0.15 \\
(0.12)\end{array}$ & $\begin{array}{l}-0.15 \\
(0.16)\end{array}$ \\
\hline & Social Connectedness & $\begin{array}{l}-0.17 \\
(0.13)\end{array}$ & $\begin{array}{l}-0.1 \\
(0.15)\end{array}$ & $\begin{array}{l}-0.15 \\
(0.16)\end{array}$ & $\begin{array}{l}-0.17 \\
(0.13)\end{array}$ & $\begin{array}{l}-0.17 \\
(0.11)\end{array}$ & $\begin{array}{l}-0.2 \\
(0.14)\end{array}$ \\
\hline & Frequency Seeing Confidante & $\begin{array}{l}0.09 \\
(0.17)\end{array}$ & $\begin{array}{l}0.21 \\
(0.21)\end{array}$ & $\begin{array}{l}-0.16 \\
(0.21)\end{array}$ & $\begin{array}{l}0.02 \\
(0.16)\end{array}$ & $\begin{array}{l}-0.03 \\
(0.15)\end{array}$ & $\begin{array}{l}0 \\
(0.18)\end{array}$ \\
\hline & Self-Efficacy & $\begin{array}{l}0.08 \\
(0.13)\end{array}$ & $\begin{array}{l}0.14 \\
(0.17)\end{array}$ & $\begin{array}{l}-0.04 \\
(0.17)\end{array}$ & $\begin{array}{l}0 \\
(0.13)\end{array}$ & $\begin{array}{l}0.1 \\
(0.11)\end{array}$ & $\begin{array}{l}0.02 \\
(0.14)\end{array}$ \\
\hline & Empowerment & $\begin{array}{l}-0.03 \\
(0.17)\end{array}$ & $\begin{array}{l}-0.08 \\
(0.2)\end{array}$ & $\begin{array}{l}-0.07 \\
(0.22)\end{array}$ & $\begin{array}{l}-0.05 \\
(0.16)\end{array}$ & $\begin{array}{l}-0.04 \\
(0.14)\end{array}$ & $\begin{array}{l}-0.03 \\
(0.18)\end{array}$ \\
\hline & Quality of Life - Global & $\begin{array}{l}-0.07 \\
(0.15)\end{array}$ & $\begin{array}{l}0.01 \\
(0.19)\end{array}$ & $\begin{array}{l}-0.12 \\
(0.19)\end{array}$ & $\begin{array}{l}-0.09 \\
(0.15)\end{array}$ & $\begin{array}{l}-0.07 \\
(0.11)\end{array}$ & $\begin{array}{l}-0.17 \\
(0.16)\end{array}$ \\
\hline & Psychiatric Symptomatology & $\begin{array}{l}0 \\
(0.17)\end{array}$ & $\begin{array}{l}-0.04 \\
(0.17)\end{array}$ & $\begin{array}{l}-0.01 \\
(0.22)\end{array}$ & $\begin{array}{l}0.1 \\
(0.12)\end{array}$ & $\begin{array}{l}0.03 \\
(0.12)\end{array}$ & $\begin{array}{l}-0.01 \\
(0.17)\end{array}$ \\
\hline \multicolumn{8}{|c|}{ Substance Use } \\
\hline & Alcohol Use Severity & $\begin{array}{l}0.07 \\
(0.17)\end{array}$ & $\begin{array}{l}-0.05 \\
(0.19)\end{array}$ & $\begin{array}{l}0.21 \\
(0.22)\end{array}$ & $\begin{array}{l}0.02 \\
(0.09)\end{array}$ & $\begin{array}{l}0.15 \\
(0.13)\end{array}$ & $\begin{array}{l}0.06 \\
(0.18)\end{array}$ \\
\hline & Substance Use Severity & $\begin{array}{l}-0.33^{*} \\
(0.16)\end{array}$ & $\begin{array}{l}-0.19 \\
(0.18)\end{array}$ & $\begin{array}{l}-0.33 \\
(0.23)\end{array}$ & $\begin{array}{l}-0.17 * * \\
(0.06)\end{array}$ & $\begin{array}{l}-0.26^{*} \\
(0.11)\end{array}$ & $\begin{array}{l}-0.21 \\
(0.17)\end{array}$ \\
\hline \multicolumn{8}{|c|}{ Service Use } \\
\hline & Cost of All Service Use & $\begin{array}{l}-0.55^{* *} \\
(0.19)\end{array}$ & $\begin{array}{l}-0.34 \\
(0.24)\end{array}$ & $\begin{array}{l}-0.47 \\
(0.26)\end{array}$ & & $\begin{array}{l}-0.44^{* *} \\
(0.15)\end{array}$ & $\begin{array}{l}-0.56^{* *} \\
(0.21)\end{array}$ \\
\hline & Cost of Shelter Use & $\begin{array}{l}-0.63 * * \\
(0.19)\end{array}$ & $\begin{array}{l}-0.39 \\
(0.22)\end{array}$ & $\begin{array}{l}-0.6^{*} \\
(0.25)\end{array}$ & $\begin{array}{l}-0.54 * * \\
(0.18)\end{array}$ & $\begin{array}{l}-0.49 * * \\
(0.15)\end{array}$ & $\begin{array}{l}-0.64 * * \\
(0.2)\end{array}$ \\
\hline \multicolumn{8}{|c|}{$\begin{array}{l}\text { Mean Absolute } \\
\text { Difference from } \\
\text { Primary Analysis }\end{array}$} \\
\hline & & - & 0.12 & 0.09 & 0.08 & 0.07 & 0.05 \\
\hline
\end{tabular}




\section{Limitations}

Although these results are promising, there are several limitations to this study. First, due to the high cost and novelty of this work, we conducted this study with a relatively small sample. Smaller samples reduce statistical power to detect effects, produce less reliable estimates, and limit the ability to test for moderators such as age and gender (Button, et al. 2013). Future research should replicate this work using larger sample sizes.

Second, the study experienced moderate levels of attrition and missed surveys over time. As a result, the statistical power of our analyses is lower at the later time points. This may partially contribute to the fact that we saw relatively fewer statistically significant results after 6 months. Attrition also presents an opportunity for self-selection, such that certain factors-such as housing status - may cause some participants to be more likely to drop out, resulting in a less representative sample. Of course, it would be particularly problematic if cash recipients who experienced no benefit were most likely to drop out. We have attempted to address this concern in several ways. First, the attrition rate was similar across conditions, which suggests that cash recipients were equally likely to drop out. Second, we conducted a logistic regression predicting dropout status from baseline demographics, such as age, gender, mental health, and substance use. Among the cash group, only substance use severity (DAST-10) was related to dropping out of the study, suggesting that individuals with more severe substance use issues may have been less likely to complete follow-up surveys. This was not the case for the non-cash group. Finally, we found similar results in our sensitivity analyses when we imputed data by carrying forward participants last recorded observation. This suggests that it is unlikely that the results are driven by missing data from participants who dropped out because of difficult circumstances.

Third, the follow-up period was limited to 12 months. Although the differences between conditions were mostly diminished by 12 -months, it is possible that some impacts-such as education or employment - may take longer to materialize.

Fourth, nine cash participants faced significant delays in obtaining government ID (e.g., over 100 days). Because ID was required in order to open a bank account, this resulted in a longer delay between the baseline survey and the date of the cash transfer. While we were able to maintain a gap of 30 days between the cash transfer and the 1-month survey, the length of time between the baseline survey and 1-month survey varied. We have tried to address this in several ways. First, we added the length of time between baseline and 1-month as a covariate and our results hold (mean absolute difference $=.12$ ). Second, we analyzed the data without these participants, and we observed the same effects (see Table S8; mean absolute difference $=.05$ ).

Finally, the lack of overall impact of the cash transfer on cognitive function, subjective wellbeing, education, and employment is inconsistent with past literature (e.g., Ong et al., 2019; Haushofer \& Shapiro, 2016). There are many factors that can explain the null effects. Although past work has shown the detrimental effect of poverty on cognitive function (Mani et al., 2013), a cash transfer may not necessarily increase cognitive function due to insufficient amount or other problems associated with the transfer (Mani et al., 2020). After all, \$7,500 in an expensive city like Vancouver is not a large amount of money, and moving into new housing and establishing new social networks can be stressful. Future research can examine whether larger amounts of cash transfer or the ease of relocation could improve cognitive function. The lack of 
impact on subjective well-being is inconsistent with past literature on cash transfers from developing countries (Haushofer \& Shapiro, 2016). Although positive affect temporarily increased at one month after the cash transfer, we did not find any effects on life satisfaction, self-efficacy, sense of empowerment, or quality of life. This means that while the cash transfer provided financial resources and freedom, it didn't influence perceptions of the self or one's life, presumably because many cash recipients were still experiencing poverty despite having moved out of homelessness. Future research can examine whether repeated cash transfers over years (e.g., basic income) can improve subjective well-being. The lack of effect on education and employment suggests that this one-time cash transfer is insufficient to allow people to enroll in courses or obtain employment, although the current impact was only one year, and long-term effects still remain to be seen. 


\section{Public Prediction of Spending on Temptation Goods}

We conducted two iterations of this experiment. Both iterations were preregistered and used nearly identical methods (first study pre-registration: osf.io/86x9z; replication study preregistration: osf.io/txqgv). The second iteration of the study was conducted as a replication of the first. The pattern of results is highly similar across both studies, so the data from both studies were combined.

\subsection{Participants}

We conducted a power analysis to determine the minimum sample size. With a minimum effect size of $d=0.5$, the sample size required to detect an effect of this size with power $=0.95$, and alpha $=0.05$ is at least 100 participants per condition (total $N=400$ ) for a given study. Over two studies, $N=1,114$ participants (final sample) were recruited from MTurk in the US and Canada and were compensated $\$ 0.25$ for participating. Participants were required to be over 18 years old and fluent in English. As described in our preregistration, participants were excluded if they failed an attention check, had knowledge of the New Leaf Project (the cash transfer experiment), completed the survey in less than 1 minute or more than 15 minutes, failed a captcha test, or if they did not complete the entire survey (a total of $n=684$ were excluded).

The sample was mostly representative of the population in the US: the average age was 40 years old, $51 \%$ were female, median annual personal income before tax was $\$ 40,000-\$ 50,000$, average political orientation was 3.82 on a scale from 1-very liberal (e.g. left wing) to 7-very conservative (e.g. right wing), $72 \%$ identified as Caucasian, $8 \%$ as African American, $5 \%$ as Latino or Hispanic, $11 \%$ as Asian, $73 \%$ lived in urban areas, and $27 \%$ lived in rural areas.

\subsection{Stimuli and Procedure}

There were four conditions in the experiment: homeless other $(n=284)$, homeless self $(n=284)$, non-homeless other $(n=270)$, and non-homeless self $(n=276)$. Below are the vignettes presented in each condition.

Homeless other: Imagine an individual who lives in a large city in North America. This individual has recently experienced some financial difficulties in their life, and has become homeless. This individual is at a low risk of mental health challenges and substance abuse. If this individual received an unconditional cash transfer of $\$ 7,500$, how much of the money would they spend on the following items over the course of one year?

Homeless self: Imagine you live in a large city in North America. You have recently experienced some financial difficulties in your life, and have become homeless. You are at a low risk of mental health challenges and substance abuse. If you received an unconditional cash transfer of $\$ 7,500$, how much of the money would you spend on the following items over the course of one year?

Non-homeless other: Imagine an individual who lives in a large city in North America. This individual has recently experienced some financial difficulties in their life. This individual is at a low risk of mental health challenges and substance abuse. If this individual received an 
unconditional cash transfer of $\$ 7,500$, how much of the money would they spend on the following items over the course of one year?

Non-homeless self: Imagine you live in a large city in North America. You have recently experienced some financial difficulties in your life. You are at a low risk of mental health challenges and substance abuse. If you received an unconditional cash transfer of $\$ 7,500$, how much of the money would you spend on the following items over the course of one year?

In the replication study, we added a further sentence to the vignette in the non-homeless conditions that says the individual is (you are) stably housed to emphasize the non-homeless status. After reading the vignette, participants were asked to predict spending over one year in the following categories and make sure the total equals $\$ 7,500$ : rent, food, clothing/shoes, transportation (bus fare, taxi etc.), spending on family members (e.g., children, parents, relatives), other recurring weekly spending (e.g., debt, medications, etc.), durable goods (e.g. computers, phones, bikes/cars, school fees, etc.), alcohol, drugs, cigarettes, gambling (e.g., lottery tickets, casinos), or other. As described in our preregistration, our primary outcome of interest was predicted spending on temptation goods (alcohol, drugs, cigarettes, gambling).

\subsection{Additional Results}

We conducted pairwise comparisons with Bonferroni corrections between the homeless other condition and each of the other three conditions. The homeless other condition was significantly greater than the homeless self $(M=181, S D=406), t(1092)=3.91, p<.001, d=0.33 \mathrm{CI} 95 \%$ $[.17, .50]$, non-homeless other $(M=170, S D=383), t(1092)=4.15, p<.001, d=0.36$ CI $95 \%$ $[.19, .53]$ and non-homeless self conditions $(M=194, S D=422), t(1092)=3.56, p<.001, d=$ 0.30 CI $95 \%[.14, .47]$.

In exploratory analyses, we also examined predicted spending on rent, which should be an approximate indicator of the extent to which participants thought the cash transfer would be used to attain stable housing. Predicted spending on rent was similar when the recipient was described as a homeless other $(M=\$ 3,318, S D=1,890)$ compared to when the recipient was described as a non-homeless individual or as the participants themselves whether homeless or not $(M=\$ 3,284$, $S D=1,915, t(1112)=0.26, p=.796, d=0.02,95 \%$ CI $[-0.12,0.15])$. The homeless other condition was not different than the homeless self $(M=\$ 3,386, S D=1,775), t(1110)=0.425, p$ $=1, d=-.04$ CI 95\% [-.20,.13], non-homeless other $(M=\$ 3,391, S D=1,888), t(1110)=0.450$, $p=1, d=-0.04$ CI 95\% [-.20,.13] and non-homeless self conditions $(M=\$ 3,075, S D=2,064)$, $t(1110)=-1.508, p=0.396, d=0.13$, CI 95\% [-.04, .29]. This suggests that participants anticipate that individuals experiencing homelessness will spend as much on rent as individuals who are housed. Thus, participants seem to recognize the potential housing stability benefits of the cash transfer for people who are homeless, yet also maintain mistrust about spending on temptation goods. 


\section{Public Support for Cash Transfer Policy}

We conducted two iterations of this experiment. Both iterations were preregistered and used identical methods (first study pre-registration: osf.io/resf3; replication study pre-registration: osf.io/3876c). The second iteration of the study was conducted as a replication of the first. The pattern of results is highly similar across both studies, so the data from both studies were combined.

\subsection{Participants}

We conducted a power analysis to determine the minimum sample size. With a minimum effect size of $d=0.5$, the sample size required to detect an effect of this size with power $=0.95$, and alpha $=0.05$ is at least 100 participants per condition (total $N=300$ ) for a given study. Over two studies, $N=1,373$ participants (final sample) were recruited from MTurk in the US and Canada and were compensated $\$ 0.25$ for participating. Participants were required to be over 18 years old and fluent in English. As described in our preregistration, participants were excluded if they failed an attention check, had knowledge of the New Leaf Project (the cash transfer experiment), completed the survey in less than 1 minute or more than 15 minutes, failed a captcha test, or if they did not complete the entire survey (a total of $n=256$ were excluded).

The sample was mostly representative of the population in the US: the average age was 38 years old, $52 \%$ were female, median annual personal income before tax was $\$ 40,000-\$ 50,000$, average political orientation was 3.71 on a scale from 1-very liberal (e.g. left wing) to 7-very conservative (e.g. right wing), 71\% identified as Caucasian, 9\% as African American, 5\% as Latino or Hispanic, $11 \%$ as Asian, $73 \%$ lived in urban areas, and $27 \%$ lived in rural areas.

\subsection{Stimuli and Procedure}

There were three conditions in the experiment: counter-stereotype condition $(n=443)$, utilitarian condition $(n=475)$, and control $(n=455)$. Below is the summary of the study presented to participants in the first two conditions. Participants in the control condition were not shown a summary of the study.

Counter-stereotype: In a pilot project based in a large city in North America, 50 homeless individuals each received a one-time unconditional cash transfer of $\$ 7,500$. These individuals did not have a severe level of substance use, alcohol use, or mental health challenges. Over the course of one year, they reduced their spending on alcohol, drugs, and cigarettes, and increased their spending on rent, food, and clothing.

Utilitarian: In a pilot project based in a large city in North America, 50 homeless individuals each received a one-time unconditional cash transfer of $\$ 7,500$. These individuals did not have a severe level of substance use, alcohol use, or mental health challenges. Over the course of one year, they moved out of the homeless shelter faster than people who did not receive the cash transfer. Their reduced reliance on the shelter system saved more money than the cash transfer itself, producing net savings for society.

After the summary, participants in all conditions were asked this question: 
How much do you support a public policy that distributes a one-time unconditional cash transfer of $\$ 7,500$ to people who are homeless and do not have a severe level of substance use, alcohol use, or mental health challenges?

Then they responded on a scale from 1 (strongly oppose) to 5 (strongly support). 